\title{
US Equity Tail Risk and Currency Risk Premia
}

Fan, Zhenzhen, Juan M. Londono, and Xiao Xiao
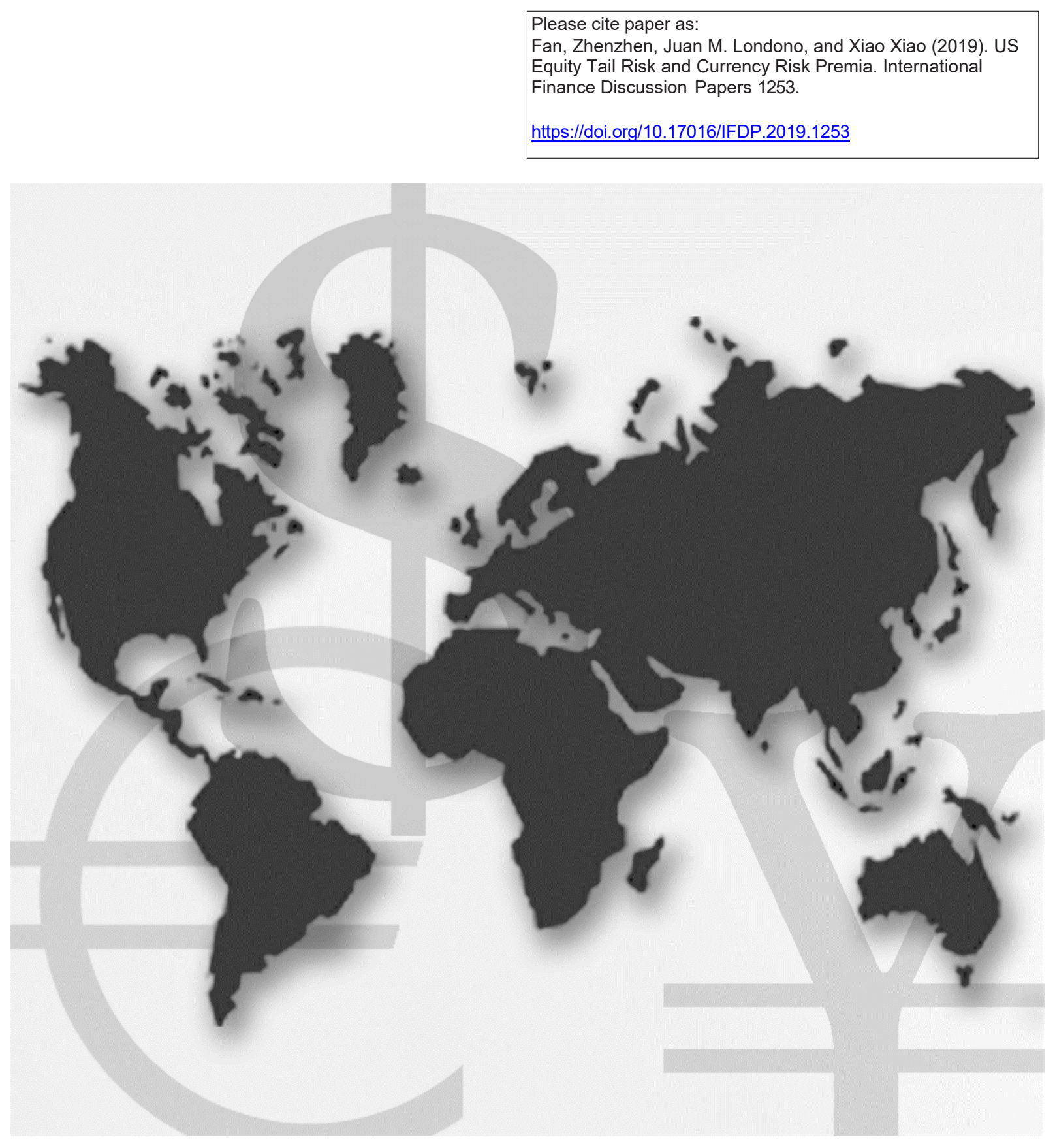

\section{International Finance Discussion Papers}

Board of Governors of the Federal Reserve System

Number 1253

July 2019 
Board of Governors of the Federal Reserve System

International Finance Discussion Papers

Number 1253

July 2019

\title{
US Equity Tail Risk and Currency Risk Premia
}

\author{
Zhenzhen Fan, Juan M. Londono, and Xiao Xiao
}

NOTE: International Finance Discussion Papers are preliminary materials circulated to stimulate discussion and critical comment. References to International Finance Discussion Papers (other than an acknowledgment that the writer has had access to unpublished material) should be cleared with the author or authors. Recent IFDPs are available on the Web at www.federalreserve.gov/pubs/ifdp/. This paper can be downloaded without charge from the Social Science Research Network electronic library at www.ssrn.com. 


\title{
US Equity Tail Risk and Currency Risk Premia*
}

\author{
Zhenzhen $\mathrm{Fan}^{\dagger} \quad$ Juan M. Londono ${ }^{\ddagger} \quad \mathrm{Xiao} \mathrm{Xiao}^{\S}$
}

This Version: July 2019

\begin{abstract}
We find that a US equity tail risk factor constructed from out-of-the-money S\&P 500 put option prices explains the cross-sectional variation of currency excess returns. Currencies highly exposed to this factor offer a low currency risk premium because they appreciate when US tail risk increases. In a reduced-form model, we show that country-specific tail risk factors are priced in the cross section of currency returns only if they contain a global risk component. Motivated by the intuition from the model and by our empirical results, we construct a novel proxy for a global tail risk factor by buying currencies with high US equity tail beta and shorting currencies with low US tail beta. This factor, along with the dollar risk factor, explains a large portion of the cross-sectional variation in the currency carry and momentum portfolios and outperforms other models widely used in the literature.
\end{abstract}

JEL Classification: G12, G15, F31

Keywords: Equity tail risk; Global tail risk; Currency returns; Carry trade; Currency momentum

${ }^{*}$ We would like to thank Ric Colacito and Michael Weber for their valuable comments. Zhenzhen and Xiao would like to thank the funding support from the Canadian Derivatives Institute. The analysis and conclusions set forth are those of the author and do not indicate concurrence by other members of the Federal Reserve Board.

${ }^{\dagger}$ School of Finance, Nankai University. Email: zhenzhen.fan@nankai.edu.cn.

${ }^{\ddagger}$ Division of International Finance at the Federal Reserve Board of Governors. Email: juan-miguel. londono-yarce@frb.gov.

${ }^{\S}$ Corresponding author. Erasmus School of Economics, Erasmus University Rotterdam. Email: xiao@ese.eur.nl. 


\section{Introduction}

This paper studies the pricing implication of US equity tail risk in the cross section of currency excess returns. The size and international linkages of the US economy have substantial implications for the global economy. The US is, after all, the largest economy in the world, according to the World Economic Outlook report published by the IMF in 2019. In terms of trade linkages, the US is the most important export destination for onefifth of all countries in the world, according to the 2018 World Bank's Global Economic Prospects report. Moreover, changes in US monetary policy play a major role in driving global financing conditions (see, for instance, Wongswan (2009)). Several recent studies show that, as a consequence of trade and financial linkages, developments in US equity markets have important implications for the pricing of international assets. For instance, Rapach, Strauss, and Zhou (2013) find evidence that US stock returns have a leading role in the predictability of international stock returns, while non-US stock returns have almost no additional predictability. Aït-Sahalia, Cacho-Diaz, and Laeven (2015) show that most equity markets tend to reflect US equity jumps quickly, while statistical evidence for the reverse transmission is much less pronounced. Bollerslev, Marrone, Xu, and Zhou (2014) and Londono (2015) find that the US equity variance risk premium has predictive power for international stock returns.

In this paper, we build on the intuition that, if a currency appreciates with respect to the US dollar when US tail risk increases, this currency is essentially a hedge against US tail risk, which makes the currency more attractive to investors and, therefore, reduces its expected returns. To measure US tail risk, we construct a portfolio that is long the CBOE Put Protection (PPUT) index and short the S\&P 500 index. The PPUT index is designed to track the performance of a hypothetical risk-management strategy that consists of a long position indexed to the S\&P 500 index and a rolling long position in monthly 5\% Out-of-the-Money (OTM) S\&P 500 put options. We define the US equity tail risk factor as the log return of this portfolio, which pays off when the price of the 
$5 \%$ put option increases. ${ }^{1}$ Thus, an increase in our measure of US tail risk implies that investors are willing to pay more to hedge the risk of a potential tail event in US equity markets. The factor can also be interpreted as the innovation of the risk-neutral left jump tail measure in Bollerslev and Todorov (2011). Our sample period runs from January 1990 to April 2018.

The equity option-implied US tail risk factor differs from other related factors in the exchange rate literature. In particular, the US tail risk factor in this paper is calculated from equity option prices and, therefore, is a risk-neutral measure of the expectations of left-tail events in the US equity market. The forward-looking nature of our measure differentiates it from existing measures of realizations of downside US (global) equity market events, such as the US (global) downside risk factor in Lettau, Maggiori, and Weber (2014) and Dobrynskaya (2014), and from measures of realizations of currency jumps, such as the measure in Lee and Wang (2018). Our measure also differs from currency volatility measures, such as the foreign exchange (FX) volatility factor in Menkhoff et al. (2012a) and the currency variance risk premium in Londono and Zhou (2017), because our tail-risk factor focuses on extreme unfavorable stock market events.

Our option-implied tail factor has several advantages with respect to other tail risk measures in the literature. First, it is publicly available and easy to replicate. Second, tail risk can be measured at a high frequency with forward-looking information extracted from tradable option prices, even though large-magnitude downside market states occur infrequently. Third, our tail-risk factor does not only contain information about the probability of left-tail jump events, such as in Lu and Murray (2018), but also contains information on investors' beliefs of the potential jump size. Fourth, our measure is constructed from asset returns and is, therefore, tradable with an intuitive interpretation.

To motivate our empirical analysis, we propose a stylized reduced-form model to assess the pricing implications of global and domestic tail risks in the cross section of currency returns. We show that if a country's tail risk factor contains a global component, expo-

\footnotetext{
${ }^{1}$ This factor can be replicated using data from OptionMetrics, although for a shorter sample starting from January 1996.
} 
sures of foreign currencies to this tail risk should matter in the cross section of currency returns. In particular, if tail risk contains a global component, 1) buying currencies with high tail beta and shorting currencies with low tail beta isolates the global component in a country's tail risk factor, and 2) the tail risk factor is priced in the cross section of currencies, irrespective of the reference currency.

Our paper makes two main empirical contributions to the literature. In our first contribution, we examine the pricing of domestic tail risk from the perspective of a US investor. Using data for 37 currencies (in units of foreign currency per US dollar) between January of 1990 and April of 2018, we find that the US tail risk factor carries a negative price of risk in the cross section of currency returns. In particular, the future returns of quintile currency portfolios sorted on US tail betas decrease monotonically. High-beta portfolios load positively on US tail risk while low-beta portfolios load negatively on this risk factor. A portfolio that longs the top quintile and shorts the bottom quintile generates a significantly negative average excess return of $-3.61 \%$ per year in the sample of all currencies and $-6.13 \%$ per year in the sample of currencies of developed markets. These return spreads cannot be explained by the dollar risk factor or by the FX volatility factor and remain robust after controlling for changes in the VIX. Thus, in light of the implications from our model, this evidence suggests that the US tail risk factor contains a global component. Consistent with the model implication that cross-sectional pricing implications hold irrespective of the reference currency, we find that US tail risk is also priced in the cross section of UK pound- and Japanese yen-denominated currencies. The high-minus-low return spread is $-3.95 \%$ and $-4.14 \%$ for UK investors and Japanese investors, respectively, in the universe of all currencies, and $-6.38 \%$ and $-6.30 \%$, respectively, in the universe of developed markets, confirming that the US tail risk has a global nature.

Motivated by the intuition from the model and by the empirical evidence for the cross-sectional implications of the US tail factor, in our second contribution, we construct a global tail factor using the high-minus-low return spread of the tail-beta-sorted currency portfolios. We use this factor along with the dollar risk factor to conduct asset 
pricing tests on the currency carry trade and momentum portfolios. Carry portfolios are constructed by sorting currencies by their interest rate differential, and momentum portfolios are constructed by sorting currencies by their excess returns in the past month. The two strategies have been shown to generate abnormally high Sharpe ratios (see, for instance, Lustig, Roussanov, and Verdelhan (2011) and Menkhoff, Sarno, Schmeling, and Schrimpf (2012b)). We find that high interest rate currencies have a negative exposure to the global tail factor and thus deliver low returns in times of increased high tail risk. Currency winners; that is, currencies that appreciate with respect to the US dollar in the past month, have lower tail beta than currency losers. Currency losers provide a hedge by yielding higher returns during high tail risk periods and thus have lower returns on average. These results suggest that excess returns to carry trade and momentum strategies can be partially understood as compensation for global tail risk.

A factor model with the global tail factor and the dollar risk factor outperforms popular models to explain the cross section of currency carry and momentum portfolios, such as the CAPM, the downside-risk CAPM, and a currency model with the dollar risk factor and the carry factor. Our evidence suggests that the cross-sectional explanatory power of our model can be attributed almost exclusively to the global tail factor. Moreover, the global tail factor has significant pricing power in the cross section of carry and momentum currency portfolios after controlling for the carry factor in Lustig, Roussanov, and Verdelhan (2011), the FX volatility factor in Menkhoff, Sarno, Schmeling, and Schrimpf (2012a), the global disaster risk factor in Gao, Lu, and Song (2018), the dollar carry and global dollar risk factor in Verdelhan (2018), and innovation in the VIX.

This paper contributes to three branches of the literature. First, this paper contributes to the literature on crash risk in currency markets. Brunnermeier, Nagel, and Pedersen (2008) find that high interest rate differentials predict negative skewness of currency returns, and conclude that carry trade returns bear currency-specific crash risk. Burnside, Eichenbaum, Kleshchelski, and Rebelo (2011) and Jurek (2014) study the contribution of crash risk to carry trade using the returns on "hedged carry trade" with currency options. In a parametric model, Chernov, Graveline, and Zviadadze (2018) find strong 
evidence for the existence of jumps in returns as well as in volatilities for each currency. Unlike these studies, which center the attention on country-specific crash risks, our paper focuses on the pricing of systematic tail risk in the cross section of currency returns. There are several papers on the importance of systematic disaster risk in the currency market. Farhi and Gabaix (2015) show that an exchange rate model with global disaster risk can reproduce the forward premium puzzle. Farhi, Fraiberger, Gabaix, Ranciere, and Verdelhan (2015) find empirical evidence that disaster risk accounts for a considerable amount of the carry trade risk premium. Our paper differs from these papers in two main aspects. First, we study the global component in the US equity tail risk factor and show that our construction can better identify the global tail risk factor. Second, we examine the pricing of these factors in the cross section of currency returns and to what extent the global tail risk factor explains the cross section of currency strategy returns, such as currency carry and momentum.

This paper also contributes to a second branch of the literature on explaining the excess return of currency carry trade and momentum. Several studies show that different variables can explain the excess return of the carry trade returns; for example, US consumption risk in Lustig and Verdelhan (2007), innovations to FX volatility in Menkhoff, Sarno, Schmeling, and Schrimpf (2012a), US equity downside risk in Lettau, Maggiori, and Weber (2014) and Dobrynskaya (2014), global long-run consumption news in Colacito, Croce, Gavazzoni, and Ready (2018), and global imbalances in Della Corte, Riddiough, and Sarno (2016). Filippou, Gozluklu, and Taylor (2018) show that the winner portfolio in the currency momentum strategy is compensated for the exposure to the global political risk of those currencies. The variables in the aforementioned papers have difficulties explaining the returns of carry and momentum strategies simultaneously. Our paper shows that the global tail risk factor and the dollar risk factor are able to explain a large portion of the cross-sectional variation in both currency carry and momentum portfolios.

Finally, this paper is related to a branch of the literature on the role of US specific shocks and global shocks in the pricing of currency returns. Lustig, Roussanov, and 
Verdelhan (2014) links the return of the dollar carry strategy to US-specific business cycle variations. Verdelhan (2018) shows that the global component of the dollar factor, which is calculated as the average appreciation rates of a set of currencies with respect to the US dollar, explains a large portion of the variation in bilateral exchange rates. A few papers specifically link developments in stock markets with currency returns. Hau and Rey (2006) find that currency returns are related to the relative performance of equity returns across countries. Londono and Zhou (2017) find that the US equity variance risk premium is a useful predictor of currency returns. In this paper, we show that US tail risk does not only contain US specific shocks, but also has a global component that is relevant for an international investor. This global component has pricing implications for the cross section of currency returns.

The remainder of the paper proceeds as follows. In Section 2, we propose a theoretical framework to understand the role of country-specific and global tail risk components in the pricing of cross-sectional currency returns. Section 3 introduces the data used in the paper used for the empirical exercises. In the empirical part of the paper, we consider US as the home country and investigate the pricing of US tail risk for the cross section of currency returns. Section 4 shows the main empirical results and robustness checks regarding the pricing of US tail risk in the cross section of currency excess return. Section 5 discusses the construction of the global tail risk factor and the results for the asset pricing tests on carry and momentum portfolios. We conclude in Section 6 .

\section{Domestic and Global Tail Risks and the Cross Sec- tion of Currency Returns}

In this section, we introduce a stylized reduced-form model to explain the role of countryspecific and global tail risks for currency returns. We start from the process for the log nominal stochastic discount factor (SDF) in each country $i$, denoted by $m_{i, t+1}$. We assume that the log nominal SDF is driven by a country specific Gaussian shock $u_{i, t+1}$, a tail shock 
Tail $_{i, t+1}$, and a global Gaussian shock $u_{g, t+1}$, as follows:

$$
-m_{i, t+1}=a_{i}+\gamma_{i} u_{i, t+1}+\lambda_{i} \operatorname{Tail}_{i, t+1}+\delta_{i} u_{g, t+1} .
$$

The three shocks in Equation (1) are independently distributed. The country-specific diffusion shock $u_{i, t+1}$ and the common diffusion shock $u_{g, t+1}$ follow normal distributions $N\left(0, \sigma_{i}^{2}\right)$ and $N\left(0, \sigma_{g}^{2}\right)$, respectively, while the country-specific tail shock Tail $_{i, t+1}$ is unfavorable in its nature and occurs in large magnitude. Potentially, this tail shock could be specified as a compound Poisson distribution. As the stylized model serves an illustrative purpose, we do not specify the exact distributional form of the tail shock in this paper. A pricing kernel like Equation (1) is standard in the equity pricing literature and could be seen as a general equilibrium result of a jump-diffusion economy, as in Wachter (2013).

We assume that the tail risk of country $i$ contains a systematic component, the global tail risk factor Tail ${ }_{t+1}^{g l o b a l}$, and an idiosyncratic component Tail $_{i, t+1}^{\text {idio }}$,

$$
\operatorname{Tail}_{i, t+1}=\zeta_{i} \operatorname{Tail}_{t+1}^{\text {global }}+\text { Tail }_{i, t+1}^{\text {idio }},
$$

where $\zeta_{i}$ is country $i$ 's loading on the global tail risk.

Assuming complete markets, the log change in the nominal exchange rate between the home country $j$ and foreign country $i, \Delta s_{j i}$, is equal to the difference of the log pricing kernels of the two countries (see, for instance, Backus et al. (2001)). That is,

$$
\Delta s_{j i, t+1}=m_{j, t+1}-m_{i, t+1}
$$

where $m_{j}$ and $m_{i}$ denote the log nominal SDF of the domestic country $j$ and any foreign country $i$, respectively. The exchange rate is expressed in units of foreign currency per domestic currency; for instance, per US dollars. In the remainder of this paper, we take the perspective of a US investor and regard the US as the home country. To keep the notation simple, we omit the home country subscript $i$ and write the currency rate $s_{j i, t+1}$ as $s_{i, t+1}$ when no confusion is caused. Thus, an increase in $s_{i}$ denotes an appreciation of 
the home currency with respect to the foreign currency.

In the model, the log change in excess currency returns is given by

$$
\begin{aligned}
& r x_{i, t+1}=\Delta s_{i, t+1}+r_{t}-r_{i, t} \\
& =a-a_{i}+\gamma u_{t+1}-\gamma_{i} u_{i, t+1}+\lambda \operatorname{Tail}_{t+1}-\lambda_{i} \operatorname{Tail}_{i, t+1}+\left(\delta-\delta_{i}\right) u_{g, t+1}+r_{t}-r_{i, t}, \\
& =a-a_{i}+\underbrace{\gamma u_{t+1}+\lambda \operatorname{Tail}_{t+1}^{i d i o}}_{\text {home country shocks }}-\underbrace{\left(\gamma_{i} u_{i, t+1}+\lambda_{i} \operatorname{Tail}_{i, t+1}^{\text {idio }}\right)}_{\text {foreign country shocks }} \\
& +\underbrace{\left(\lambda_{i} \zeta_{i}-\lambda \zeta\right) \text { Tail }_{t+1}^{\text {global }}+\left(\delta_{i}-\delta\right) u_{g, t+1}}_{\text {global shocks }}+r_{t}-r_{i, t},
\end{aligned}
$$

where $r$ and $r_{i}$ represent the domestic and foreign risk-free interest rates, respectively.

If the country-specific shocks are diversifiable, only global shocks will be priced in the cross section of currency returns. Intuitively, if a currency appreciates with respect to the US dollar when the global tail risk increases, this currency is essentially a hedge against global tail risk, which makes the currency more attractive to investors and yields lower expected returns. Since Tail ${ }^{\text {global }}$ is not directly observable empirically, we instead focus on the conditional beta of currency excess return to the domestic tail factor Tail, which has a global component. In the model, the corresponding conditional beta of the currency excess return on the US tail-risk factor (Tail), $\beta_{\text {Tail }, i, t}$, is

$$
\beta_{\text {Tail }, i, t}=\frac{\operatorname{cov}_{t}\left(r x_{i, t+1}, \text { Tail }_{t+1}\right)}{\operatorname{var}_{t}\left(\text { Tail }_{t+1}\right)}=\frac{\zeta\left(\lambda_{i} \zeta_{i}-\lambda \zeta\right) \operatorname{var}_{t}\left(\text { Tail }_{t+1}^{\text {global }}\right)-\lambda \operatorname{var}_{t}\left(\text { Tail }_{t+1}^{\text {idio }}\right)}{\operatorname{var}_{t}\left(\text { Tail }_{t+1}\right)}
$$

If the tail risk of the home country, Tail , is not exposed to the global tail component $(\zeta=0$ in Equation $(2)), \beta_{\text {Tail }, i, t}$ is equal to $-\lambda$ for all foreign currencies. If $\zeta \neq 0$, the conditional beta of foreign currency $i$ varies across currencies for different exposures of the country's tail factor to the global tail factor, $\zeta_{i}$.

Meanwhile, the conditional beta of the currency excess return on the global tail risk 
factor, $\beta_{\text {Tail }, i, t}^{\text {Global }}$, is

$$
\beta_{\text {Tail }, i, t}^{\text {Global }}=\frac{\operatorname{cov}_{t}\left(r x_{i, t+1}, \text { Tail }_{t+1}^{\text {Global }}\right)}{\operatorname{var}_{t}\left(\text { Tail }_{t+1}^{\text {Global }}\right)}=\frac{\left(\lambda_{i} \zeta_{i}-\lambda \zeta\right) \operatorname{var}_{t}\left(\text { Tail }_{t+1}^{\text {global }}\right)}{\operatorname{var}_{t}\left(\text { Tail }_{t+1}^{\text {Global }}\right)}
$$

Comparing Equation (5) with (4), we can see that sorting currencies by $\beta_{\text {Tail, i,t }}$ is equivalent to sorting them by $\beta_{\text {Tail }, i, t}^{\text {Global }}$. Hence, when $\beta_{\text {Tail }, i, t}^{\text {Global }}$ is not observable, $\beta_{\text {Tail }, i, t}$ can be used as a proxy of $\beta_{\text {Tail }, i, t}^{\text {Global }}$, as long as $\zeta \neq 0$.

Tail-beta sorted portfolios are useful to extract the global component of any domestic tail risk factor. We define the long-short portfolio of buying high tail beta currencies and shorting low tail beta currencies as Global Tail:

$$
\text { Global Tail } \text { Th1 }_{t}=\frac{1}{N_{H_{\beta}}} \sum_{i \in H_{\beta}} r x_{i}-\frac{1}{N_{L_{\beta}}} \sum_{i \in L_{\beta}} r x_{i},
$$

where $N_{H_{\beta}}$ and $N_{H_{\beta}}$ denote the number of currencies in the high $\left(H_{\beta}\right)$ and low $\left(L_{\beta}\right)$ tailbeta portfolios, respectively. In this long-short portfolio, idiosyncratic tail risks cancel out and the portfolio return is dominated by the global tail risk component. When $N \rightarrow \infty$, the global component of the tail risk factor is thus:

$$
\lim _{N \rightarrow \infty} \text { Global Tail }{ }_{t+1}=\left(\bar{\beta}_{t}^{H_{\beta}}-\bar{\beta}_{t}^{L_{\beta}}\right) \text { Tail }{ }_{t+1}^{\text {global }} .
$$

Therefore, the long-short tail beta portfolio can isolate the global tail component from the purely idiosyncratic tail risk factor. The common components in any country's tail factors capture systematic risk that cannot be diversified away and should therefore carry risk premia.

An interesting implication of our framework is that the long-short tail beta portfolio can be constructed for currency excess returns expressed in any currency. For example, to calculate the global tail risk factor, we could consider the cross section of currency- $m$ denominated currencies instead of the US-dollar-denominated currencies. In principle, the long-short beta portfolio with base currency $m$ should generate a significant return, 
given that the tail risk factor of country $m$ has a global component.

An alternative way of constructing a global tail risk factor in the literature is to aggregate the tail risk factor of individual currencies, such as in Rafferty (2012) and Gao, Lu, and Song (2018). Suppose we are able to extract the tail risk from currency returns.

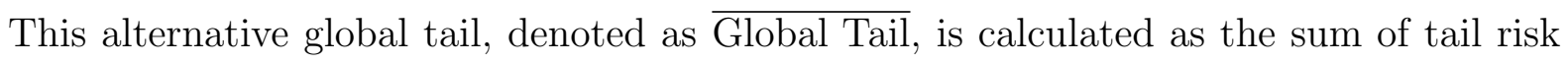
in all currencies:

$$
\begin{aligned}
\overline{\text { Global Tail }} & \equiv \sum_{i=1}^{n}\left(\lambda_{i} \text { Tail }_{i, t+1}\right)-n \lambda \text { Tail }_{t+1} \\
& =\left(\sum_{i=1}^{n} \lambda_{i} \zeta_{i}-n \lambda \zeta\right)\left(\text { Tail }_{t+1}^{\text {global }}\right)+\left(\sum_{i=1}^{n} \lambda_{i}-n \lambda\right)\left(\text { Tail }_{t+1}^{\text {idio }}\right) .
\end{aligned}
$$

Unlike our Global Tail factor, which, by construction, has a positive exposure to Tail global $^{\text {a }}$ at all times, the exposure to Tail ${ }^{\text {global }}$ in Global Tail,$\left(\sum_{i=1}^{n} \lambda_{i} \zeta_{i}\right)-n \lambda \zeta$, could be positive, negative, or even trivial. If any of the parameters $\lambda_{i}, \lambda, \zeta_{i}$, or $\zeta$ is time-varying, whether this exposure is consistently positive or negative cannot be guaranteed. Our Global Tail factor is, therefore, a cleaner measure of Tailglobal than $\overline{\text { Global Tail. }}$

To sum up, our framework suggests that if the tail risk factor of the home country has a global component, the conditional exposure (beta) of foreign currency excess returns to this risk factor varies across countries. Moreover, each country's conditional beta can be used as a proxy for the country's currency exposure to the global tail risk factor, which is unobserved. Therefore, our framework also implies that a long-short tail beta sorted currency portfolio has positive exposure to the global tail risk factor and can be used as a proxy for the global tail risk factor.

In the remainder of the paper, we provide empirical evidence for the implications of our theoretical framework. In particular, considering the US as the baseline domestic country, we first examine whether the US tail factor bears a risk premium in the cross section of currency returns. Then, in the asset pricing tests, we investigate up to what extent the Global Tail factor obtained from long-short tail beta portfolios can explain the excess returns of currency portfolios such as carry trade and momentum portfolios. 


\section{Data}

This section describes our equity and exchange rate data used in the construction of the proxy for US equity tail risk and the carry and momentum portfolios.

\subsection{US Equity Tail Risk Factor}

To calculate the US equity tail risk factor, we obtain historical prices for the S\&P 500 index and for the Put Protection (PPUT) index from the Chicago Board Options Exchange (CBOE). The PPUT index is constructed by CBOE to track the performance of a hypothetical strategy that holds a long position indexed to the S\&P 500 and buys a monthly 5\% out-of-the-money (OTM) S\&P 500 index put option. We use the PPUT index from CBOE instead of constructing the same index using OptionMetrics because the CBOE PPUT index has a longer history, dating back to 1986, while OptionMetrics data starts in 1996.

After the expiration day of each month, a unit of the S\&P 500 index and a unit of a $5 \%$ OTM put option are purchased simultaneously. The strike of the put option selected is the first available strike below the $95 \%$ of the last disseminated value of the S\&P 500 index before 11:00 am ET. The put option is purchased at a volume-weighted average trade price between 11:30 am and 12:00 pm ET. If there is no trade in the put option during the period, the last ask quote option before 12:00 pm ET is used. Typically, on the third Friday (roll day) of every month since the initial roll date, the old put option settles at 9:30 am ET against the special opening quotation of the S\&P 500 index. A new 5\% OTM monthly put option will be subsequently purchased.

To measure the US tail risk, we construct a zero-investment strategy that longs the CBOE PPut index and shorts the S\&P 500 index. The log return of this strategy is the US equity tail risk, and we refer to it as Tail hereafter. Thus,

$$
\text { Tail }_{t}=\left(\log \left(\mathrm{PPut}_{t}\right)-\log \left(\mathrm{PPut}_{t-1}\right)\right)-\left(\log \left(\mathrm{SPX}_{t}\right)-\log \left(\mathrm{SPX}_{t-1}\right)\right)
$$


where SPX is the price of the S\&P 500 index. This zero-investment strategy pays off when the price of the S\&P 500 index drops by $5 \%$ or more during the expiration period of the option. Alternatively, if we rewrite Tail as $\left(\log \left(\mathrm{PPut}_{t} / \mathrm{SPX}_{t}\right)\right)-\left(\log \left(\mathrm{PPut}_{t-1} / \mathrm{SPX}_{t-1}\right)\right)$, Tail can be interpreted as the innovation of the risk-neutral left jump tail measure in Bollerslev and Todorov (2011). Tail increases with the price of the OTM put option, which implies increased investors' desire to hedge against large index price drops within the next month. From the perspective of a US investor, Tail $_{t}$ corresponds to the tail risk factor in the home country in the model in Section 2.

Table 1 shows a set of summary statistics for Tail. For comparison, we also show summary statistics for a set of US equity- and currency-related factors used throughout the paper. In particular, we calculate the excess return of the S\&P 500 index (MKT), monthly innovations in the VIX index $(\Delta \mathrm{VIX})$, the dollar risk factor in Lustig et al. (2011) (DOL), the carry trade risk factor in Lustig, Roussanov, and Verdelhan (2011) (CARRY), and the change in volatility of the foreign exchange market ( $\Delta \mathrm{FXvol})$, which is calculated following Menkhoff, Sarno, Schmeling, and Schrimpf (2012a).

The Tail factor is, on average, negative with mean $-0.09 \%$. The distribution of this factor deviates substantially from the normal distribution, with a positive skewness and a high kurtosis (45.59\%). Compared with the VIX innovation, the Tail factor is, on average, smaller (less negative mean), and displays less volatility but much higher skewness and kurtosis. In panel B of Table 1, we show the correlation among all factors. The tail risk factor is highly negatively correlated with the excess market return $(-0.61)$ and positively correlated with the VIX innovation (0.43). Correlations between Tail and the dollar and carry factors are also negative (-0.29 and 0.16, respectively). Finally, the correlation between Tail and the innovation in currency volatility is relatively small and positive (0.18).

Figure 1 plots the time series of the S\&P 500 return and the Tail risk factor for the sample period running from February 1990 to April 2018. As can be seen from the figure, the Tail factor tends to have extremely positive values around episodes of large negative jumps in the time series of S\&P 500 returns. 


\subsection{Spot and Forward Exchange Rates}

We obtain spot and 1-month forward exchange rates with respect to the US dollar from Barclays Bank International (BBI) and WM/Reuters via DataStream. Spot and forward rates used for the empirical exercises are end-of-the-month data and are quoted as foreign currency units per US dollar. Our exchange rate data spans the period from December 1989 to April 2018. The exchange rate database from WM/Reuters only starts in 1993. Therefore, observations for the period before 1993 are obtained from BBI.

Our sample consists of the following 37 countries: Australia, Brazil, Bulgaria, Canada, Croatia, Cyprus, Czech Republic, Denmark, Egypt, the euro area, Greece, Hong Kong, Hungary, Iceland, India, Indonesia, Israel, Japan, Kuwait, Malaysia, Mexico, New Zealand, Norway, the Philippines, Poland, Russia, Saudi Arabia, Singapore, Slovakia, Slovenia, South Africa, South Korea, Sweden, Switzerland, Taiwan, Thailand, and the UK. Note that we do not include the 10 countries that adopted the euro in $1999 .{ }^{2}$ We remove the rest of the euro-area countries after their adoption of euro. Following Lustig et al. (2011), we also remove the observations that display large failures of covered interest rate parity: Malaysia from the end of August 1998 to the end of June 2005 and Indonesia from the end of December 2000 to the end of May 2007. We also consider a subsample of currencies including only the following developed markets: Australia, Canada, Denmark, the Euro area, Hong Kong, Israel, Japan, New Zealand, Norway, Singapore, South Korea, Sweden, Switzerland, and the UK. This reduced sample allows us to assess the robustness of our results to issues like liquidity and tradability.

The monthly excess return for holding foreign currency $k$, from the perspective of a US investor, is calculated as follows:

$$
r x_{t}^{k}=\left(i_{t-1}^{k}-i_{t-1}\right)-\left(s_{t}^{k}-s_{t-1}^{k}\right) \approx f_{t-1}^{k}-s_{t}^{k},
$$

\footnotetext{
${ }^{2}$ These countries are: Austria, Belgium, Finland, France, Germany, Italy, Ireland, the Netherlands, Portugal, and Spain. Because our exchange rate sample starts in 1990 and the sample for our equity tail index starts even later, there are few observations for these countries' currencies after 1990. In addition, these countries' currencies typically comoved greatly before they were officially replaced by the euro.
} 
where $i_{t}^{k}$ and $i_{t}$ are the interest rates of a foreign country and the US, respectively, and $f$ and $s$ denote the logarithm of the forward and spot rates, respectively.

\section{US Equity Tail Risk and the Cross Section of Cur- rency Returns}

In Section 2, we show that if the tail risk factor of the home country has a global component, excess returns of foreign currencies would have different exposures to this tail risk factor. In particular, investors are willing to pay a premium for currencies with negative exposures to this tail component, as these currencies offer a hedge against an increase in tail risk. Moreover, we also show that the return of a portfolio that is long in the high tail beta currencies and short in the low tail beta currencies isolates the global component of the tail risk factor.

In this section, we test the main implications of our reduced-form model by considering the US as the home country. In the first part, we show that sorting currencies by their exposure to US equity tail risk produces a novel cross section of currency returns. Our results hold irrespective of the reference currency. In particular, we show that the US equity tail risk factor is also priced in the cross section of currency returns with respect to the UK pound and the Japanese yen. In the second part, we construct a global tail risk factor and test its asset pricing implications for the cross section of carry and momentum portfolios.

\subsection{Currency Portfolios Sorted by US Equity Tail Exposures}

To assess whether the US equity tail risk is priced in the cross section of currency returns, we sort currencies into five portfolios depending on their lagged US tail risk betas. To do so, we estimate the following regression for each currency's monthly excess return, $r x_{i}$, 
using a rolling window of 60 months:

$$
r x_{i, t}=\alpha_{i}+\beta_{m, i} r_{m, t}+\beta_{\text {Tail }, i} \text { Tail }_{t}+\varepsilon_{i, t}
$$

where $r_{m, t}$ is the return of the S\&P 500 index, Tail $_{t}$ is the US equity tail risk factor, which is calculated as explained in Section 3.1, and $\varepsilon_{i, t}$ is an error term. We sort currencies into five portfolios on the estimates of $\beta_{\text {Tail, } i}$, with Portfolio 1 containing currencies with the lowest $20 \%$ tail betas and Portfolio 5 those with the highest $20 \%$ tail betas.

Figure 2 shows the time series of tail betas for each of the quintile portfolios. During most of the sample, the bottom quintile portfolio (P1 or tail-prone portfolio) has negative betas, while the top quintile portfolio (P5 or tail-resistant portfolio) has positive betas. The figure shows that there is substantial time variation in all portfolios' tail betas and in the dispersion among betas. In particular, soon after the Asian crisis of the late 1990s and the 2008 financial crisis, the gap between the beta of the lowest quintile portfolio and that of the highest quintile portfolio increases. The increase in the gap during crises suggests that the distinct hedging potential against US equity tail risk of tail-prone and tail-resistant currencies strengthens during market downturns.

Table 2 reports the descriptive statistics of the tail beta sorted portfolios, Panel A reports the statistics for all the currencies in our sample. The "Average" column is the average return of Portfolio 1 to 5. H-L is the strategy that buys Portfolio 5 and sells Portfolio 1. All portfolios are equally weighted.

Investing in currencies with high tail betas - those that provide a hedge against US tail risk - yields a significantly lower return than investing in low tail beta currencies. The average excess return decreases monotonically from Portfolio 1 to Portfolio 5. We break the currency excess return into interest rate differentials and exchange rate returns. Table 2 reports the latter component, labeled "FX return". We can see that the FX return also monotonically decreases from Portfolio 1 to Portfolio 5, suggesting that tail beta not only predicts future excess returns, but also predicts future exchange rate returns. As a consequence, the high-minus-low portfolio (H-L) yields an average annual return of 
$-3.6 \%$, which is highly statistically significant, and a Sharpe ratio of -0.54 .

The pre-formation tail betas show a symmetric pattern. The average tail beta of Portfolio 1 is -0.46 , and the average beta of Portfolio 5 is 0.46 . The table also shows pre- and post-formation forward discounts for the five portfolios. The forward discount (pre-FD) displays an increasing trend from Portfolio 1 to Portfolio 5, suggesting that these portfolios share some similarities with the carry trade portfolios. In particular, our results suggest that countries in which currencies have high exposure to US tail risk typically have higher interest rates than the US. Hence, sorting on US tail risk exposure shares some similarities with sorting on interest rate differentials. We also observe that FX return monotonically decreases from Portfolio 1 to Portfolio 5, suggesting that tail beta not only predicts interest rate differentials, but also future exchange rate returns. In addition, the excess return of the portfolio in the pre-formation month $(\mathrm{RX}(-1,0))$ decreases from Portfolio 1 to Portfolio 5, suggesting that currencies with low tail beta currencies coincide with the "winner" currencies in the momentum portfolio. In sum, our results indicate that US equity tail-beta sorted portfolios bear both features of carry and momentum portfolios.

Panel B reports the descriptive statistics for the subsample of currencies from developed markets. For this subsample of currencies, the high-minus-low tail beta portfolio yields an annual return of $-6.13 \%$, which is significant at any standard confidence level. Moreover, the average return of this portfolio is considerably higher than the return for the same portfolio for all currencies. The Sharpe ratio for this portfolio is as high as -0.74 , even higher than that for the sample of all currencies $(-0.54)$, suggesting that our results are not driven by currencies in emerging markets and their associated sovereign risks.

The statistics in Table 2 uncover several interesting facts about the tail-beta-sorted portfolio returns. First, the return of the H-L portfolio stems from the long component of the portfolio as well as from its short component. The mean excess returns of the long (P5) and short (P1) portfolios are comparable in magnitude, especially for the subsample of developed market currencies. Second, both interest rate differentials and spot exchange 
rate changes contribute to the excess returns of the $\mathrm{H}-\mathrm{L}$ portfolio. For the sample with all currencies, FX return accounts for half of the excess return in the H-L portfolio. For the subsample of developed market currencies, of the $-6.13 \%$ annual excess returns, $-4.65 \%$ comes from spot rate changes, which accounts for more than $75 \%$ of the total excess returns. This result implies that equity tail risk can predict the cross section of spot exchange rate returns, especially for the developed markets. Third, the pre-formation betas are negative for three portfolios and positive for two portfolios, suggesting that some currencies co-move with Tail while some have hedging potential against US equity tail risk. Fourth, unlike carry and momentum strategies, in which emerging markets yield better performance than developed markets, the return of the H-L portfolio is stronger if we consider only the currencies of developed markets.

To take a closer look at how often each currency enters the long or short portfolios, Table 3 reports the top 10 most often invested currencies in each of these portfolios. Panel A shows the top ten currencies in the short (P1) and long portfolios (P5) for the sample of all currencies, while Panel B shows the currencies when we consider only developed markets. Australia, New Zealand, Norway, and Canada appear in P1 in both panels. The currencies in these countries typically have negative tail betas and, therefore, depreciate against the US dollar when US equity tail risk increases. Countries such as the UK and Japan are on the top list of P5 for both samples of currencies. Thus, these currencies seem to be more resilient to US tail risk shocks. As expected, investment currencies, such as the Australian dollar and the Canadian dollar appear in the tail-prone portfolio (P1), while safe-haven currencies like the Japanese yen appear in the tail-resistant portfolio (P5).

\subsection{Other Reference Currencies}

The intuition from the model introduced in Section 2 suggests that if the tail risk factor of the home country has a global component, the tail-beta-sorted portfolios should exhibit a spread even if the cross section of currencies are not denominated in the home currency. To test this implication, we assess whether the US equity tail risk factor is priced in the 
cross section of currencies with respect to the UK pound and the Japanese yen.

We estimate the tail beta in the cross section of pound-denominated or yen-denominated currency returns and sort the currencies into five quintiles. The results are shown in Tables 4 and 5 for the pound and the yen, respectively. Indeed, the results from the point of view of a US investor remain robust if we consider other reference currencies. That is, the return of the $\mathrm{H}-\mathrm{L}$ portfolio is negative and significant for both reference currencies, the UK pound and the Japanese yen, and for both samples, that with all currencies and the subsample with the currencies of developed markets. In fact, the average H-L return spreads are even higher than those from the cross section of US-dollar-denominated currency returns.

Table 6 reports the correlation matrix of tail-beat-sorted returns (our estimation of the Global Tail risk factor) constructed from different base currencies. "US," "Japan," and "UK" represent the tail-beta-sorted returns for the all-currency sample with USD, JPY, and GBP as base currencies, respectively. "US DM", "JP DM" and "UK DM" are their corresponding counterparts in the developed markets sample. We observe that the tailbeta sorted return spreads are highly correlated among the different base currencies and irrespective of the sample of currencies. In both the all-currency sample or the developedmarket sample, the pairwise correlation of the Global Tail factor for the different base currencies is around 0.9 and can be as high as 0.98 . The correlations between the Global Tail factors of different samples with the same base currency are lower, at around 0.5 to 0.6. This table shows that the construction of the Global Tail factor is robust to the choice of the home currency.

Overall, by sorting the cross section of currency returns into quintiles according to their exposure to US tail risk, we find a novel cross section of currency returns with a monotonic pattern and a risk-return trade-off. Our results suggest that currencies with high US equity tail beta, which hedge against US equity tail risk, have lower returns on average. Moreover, tail betas are related to both carry and momentum currency portfolios. 


\subsection{Can FX Factors Explain the Tail-Beta Sorted Portfolios?}

Next, we explore how the tail-beta sorted portfolios relate to well-established common factors in currency markets. To do so, we regress the returns of each portfolio on the Dollar and FX volatility factors. The Dollar factor is the equally-weighted cross-sectional average of foreign currency excess returns with respect to the US Dollar. This factor corresponds to the return of a strategy that borrows money in the United States and invests it in global money markets outside of the United States. Lustig, Roussanov, and Verdelhan (2011) find that the Dollar factor coincides with the first principal component of the currency returns and accounts for a large fraction of the cross-sectional variation in currency excess returns. The FX volatility factor proposed by Menkhoff, Sarno, Schmeling, and Schrimpf (2012a) is the equally-weighted cross-sectional average of realized volatility of foreign currency excess returns with respect to the US Dollar. The Dollar and FX volatility factors can be regarded as measures associated with the first and second moment of global currency returns.

We run time-series regressions of the excess returns of each tail-beta portfolio, $p_{j, t}$, on the Dollar factor, DOL, and the innovation of the FX volatility factor, $\triangle \mathrm{FXvol}$, as follows:

$$
p_{j, t}=\alpha_{j}+\beta_{1, j} \mathrm{DOL}_{t}+\beta_{2, j} \Delta \mathrm{FXvol}_{t}+\epsilon_{j, t} .
$$

The regression results are reported in Table 7 . Irrespective of whether we consider all currencies or just those from developed markets (Panels A and B, respectively), the coefficients associated with $\Delta \mathrm{FXvol}$ or DOL do not exhibit any monotonic trends, although they are statistically significant for some portfolios. For both samples of currencies, $\hat{\alpha}_{j}$ 's have a monotonically decreasing pattern across tail-beta sorted portfolios, indicating that the difference in excess returns of the cross-section portfolios is not explained by the currency factors. In addition, the $\hat{\alpha}_{j}$ 's of the high-minus-low portfolios are negative and statistically significant. The tail-beta sorting strategy generates an annual alpha of $-3.44 \%$ and $-6.15 \%$ for the sample with all currencies and for that with only developed 
markets, respectively, both significant at any standard confidence level. While the currency factors explain a good amount of the time-series variation for each portfolio, they hardly capture any time series variation in the high-minus-low portfolios, with a $2 \% R^{2}$ for the sample with all currencies and a $1 \% R^{2}$ for the sample with only developed markets. Our results then demonstrate that the dollar and carry risk factors cannot explain the cross section of tail-beta sorted portfolios.

\subsection{Tail-Beta-Sorted Portfolio Controlling for the VIX}

Since the US equity tail factor, Tail, is constructed from OTM put returns, it contains information about both volatility and jump risk. As shown in Andersen, Bondarenko, Todorov, and Tauchen (2015), short-maturity deep OTM put options load mostly on the negative jump intensity and have hardly any exposure to the diffusive volatility. However, the US tail factor might still be partially attributed to equity volatility risk. In this section, we add the innovation of the CBOE VIX index, $\triangle V I X$, to the individual currency regressions to control for the volatility risk exposure. We run the following regression:

$$
r x_{i, t}=\alpha_{i}+\beta_{m, i} r_{m, t}+\beta_{\mathrm{VIX}, i} \Delta \mathrm{VIX}_{t}+\beta_{\text {Tail }, i \operatorname{Tail}_{t}}+\varepsilon_{i, t} .
$$

Then, we follow the approach in Section 4.1 and sort the currency excess returns into five quintiles according to the estimated regression coefficient $\beta_{\text {Tail }, i}$. Table 8 shows the results. Panel A shows the statistics of the portfolios sorted by the OLS estimator $\hat{\beta}_{\text {Tail }, i}$ using all currencies and Panel B shows the results for the developed markets. The highminus-low (H-L) returns remain significantly negative with substantial contribution from spot exchange rate changes. The Sharpe ratios of this tail-beta sorting strategy are only slightly smaller in magnitude, compared with those reported in Table 2. Therefore, we can conclude that sorted portfolio characteristics do not change qualitatively after controlling for innovations to the VIX. 


\section{The Price of Global Tail Risk in the Cross Section of Currency Excess Returns}

In Section 4, we find that the portfolio of currencies that provide a hedge against US tail risk has lower interest rate differentials and currency momentum than the portfolio of currencies highly exposed to US tail risk. This evidence suggests that the long-short tail-beta sorted portfolio can potentially explain the cross section of returns of the carry and momentum currency portfolios. Moreover, in Section 2, we show that the return of the long-short tail-beta-sorted portfolio can isolate the global component of a country's tail risk factor from its purely idiosyncratic component. In this section, we construct the Global Tail risk factor using the long-short tail-beta-sorted portfolio and test its asset pricing performance in the cross section of currency excess returns. In particular, we focus on carry and momentum currency portfolios.

\subsection{Carry and Momentum Portfolios}

We construct five monthly rebalanced carry trade portfolios following Lustig, Roussanov, and Verdelhan (2011) and other studies in the recent currency literature. ${ }^{3}$ At the end of each month, we sort the currencies in our sample into five portfolios based on their forward discount rates; that is, the differences between the forward FX rate and the spot FX rate. Sorting on forward discount rates is equivalent to sorting on interest rate differentials since covered interest parity holds closely, as shown by Akram et al. (2008), among others. Portfolio 1 contains the bottom $20 \%$ of currencies with the lowest interest rate differentials relative to the United States and portfolio 5 contains the top $20 \%$ of currencies with the highest interest rate differentials. The high-minus-low return of the carry portfolios is referred to as the CARRY factor in the literature, and it corresponds to borrowing in the money markets of low interest rate countries and investing it in the money markets of high interest rate countries.

\footnotetext{
${ }^{3}$ For example, Bakshi and Panayotov (2013), Daniel et al. (2017) and Bekaert and Panayotov (2019).
} 
Menkhoff, Sarno, Schmeling, and Schrimpf (2012b) find that currencies with higher returns in the past month have on average higher returns in the next month(s). As in that paper, we construct five momentum portfolios by sorting the currencies in our sample based on one-month-lagged excess returns. We assign the bottom $20 \%$ of all currencies with the lowest lagged excess returns to portfolio 1 (loser portfolio) and the top $20 \%$ of all currencies with the highest lagged excess returns to portfolio 5 (winner portfolio).

We present the summary statistics of the carry and momentum portfolios in Table 9. Panel A shows the statistics for the excess returns of carry portfolios for all currencies. Consistent with previous studies (e.g., Burnside et al. (2011), Lustig et al. (2011), among others), the carry strategy (H-L) delivers a sizable average excess return of $6.6 \%$ annually, with a Sharpe ratio of 0.76 . Average returns monotonically increase when moving from portfolio 1 to portfolio 5 . The H-L returns are skewed to the left, suggesting the presence of crash scenarios in this strategy. Panel B shows the results for the excess returns of momentum portfolios for all currencies. Consistent with Menkhoff, Sarno, Schmeling, and Schrimpf (2012b) and Filippou and Taylor (2017), the momentum strategy in the all countries universe also generates considerable excess returns of $7.6 \%$ per year.

\subsection{Asset Pricing Tests}

As shown in Section 2, the US tail risk factor explains the cross section of currency returns when it contains a global component that is relevant for all currencies. We also show that the US tail-beta-sorted long-short returns can isolate the US specific risk component and identify the global tail component. As suggested in the literature (see, for instance, Verdelhan (2018)), carry returns are mainly exposed to global shocks rather than to country-specific shocks. Moreover, inspired by the evidence in Table 2, which shows that portfolios with high tail risk beta have low interest rate differentials and low currency returns in the past month, we conjecture that the global component of the US tail risk factor might help us understand the risk-return profile of carry trade and momentum strategies in the currency market.

In this section, we test the pricing power of the tail-beta-sorted return spread or 
Global Tail for the cross-section of carry and momentum portfolios. We run the standard two-stage Fama-MacBeth regression. In the first stage, we run the following time-series regression of the excess returns of each currency portfolio $i$ on the dollar and global tail factors:

$$
r x_{i, t}=\alpha_{i}+\beta_{D O L, i} D O L_{t}+\beta_{\text {Global-Tail }, i} \text { Global Tail }_{t}+\varepsilon_{i, t},
$$

where "Global Tail" is the H-L return of the tail-beta sorted portfolios, which isolates the global component in the US equity tail risk. We control for DOL, the dollar risk factor introduced in Section 4.3, following standard practice. Having obtained estimates of the coefficients associated with the dollar factor and Global Tail, $\hat{\beta}_{D O L, i}$ and $\hat{\beta}_{\text {Global-Tail, } i}$, respectively, in a second stage, we run the following cross-sectional regression:

$$
\overline{r x}_{i}=\hat{\beta}_{D O L, i} \lambda_{D O L}+\hat{\beta}_{\text {Global-Tail }, i} \lambda_{\text {Tail }}+\eta_{i},
$$

where the dependent variable $\overline{r x}_{i}$ is the time-series average of the excess return of portfolio $i$; the first stage estimators, $\hat{\beta}_{D O L, i}$ and $\hat{\beta}_{G l o b a l-T a i l, i}$, are used as explanatory variables; $\lambda_{D O L}$ and $\lambda_{\text {Tail }}$ are the risk prices of the dollar and tail factors, respectively; and $\eta_{i}$ is the pricing error of portfolio $i$. Following Lettau et al. (2014), we calculate the cross-section $R^{2}$ as:

$$
R^{2}=1-\frac{\sum_{i=1}^{N} \hat{\eta}_{i}^{2}}{\sum_{i=1}^{N}\left(\overline{r x}^{2}\right)} .
$$

After estimating the parameters from the second-stage regression, we calculate the modelpredicted excess return as $\hat{r x}_{i}=\hat{\beta}_{D O L, i} \hat{\lambda}_{D O L}+\hat{\beta}_{\text {Global-Tail }, i} \hat{\lambda}_{\text {Tail }}$ and the root mean squared error (RMSE) as $\sqrt{\frac{1}{T} \sum_{t=1}^{T}\left(\overline{r x}_{i, t}-\hat{\overline{r x}}_{i, t}\right)^{2}}$.

Table 10 shows the first-stage Fama-Macbeth time-series regression results for the carry and momentum portfolios in Panels A and B, respectively. In the table, we report the estimated regression coefficients, t-statistics for standard errors adjusted by Newey and West (1987) with 12 lags, and adjusted $R^{2}$ 's. We find that the coefficient associated with Global Tail exhibits a decreasing pattern for both carry and momentum 
portfolios, suggesting that currencies with high interest rate differentials and past returns ("winners") have, on average, lower exposures to the global tail risk factor. Because the Global Tail factor bears a negative price of risk, currencies with low exposures to this factor should, on average, have high expected returns. Hence, the global tail risk potentially provides a risk-based explanation for the returns of carry and momentum strategies.

We also observe that the dollar risk factor and the global tail risk factor can explain a large portion of the time-series variation of carry and momentum quintile portfolios with $R^{2}$ 's above 0.6 in all cases. However, these two factors can hardly explain the time-series variation of the high-minus-low strategy returns. The $R^{2}$ 's for these strategies range from 0.06 to 0.10 . Thus, our results suggest that the Global Tail factor can partially explain the cross-sectional variation of carry and momentum, while it is still difficult to explain the average return of these strategies in the time-series dimension.

To compare the relative cross-sectional pricing performance of a specification with the dollar and global tail factors, we also consider a CAPM, a downside risk CAPM (DR-CAPM), and the FX factor model. Following Dobrynskaya (2014), we define the DR factor as $D R_{t}=r_{m, t} 1_{\left\{r_{m, t}<0\right\}}$. Following Lustig et al. (2011), we include DOL and CARRY in the FX factor model, the same two factors we use to explain the cross-section of tail-beta sorted portfolios in Section 4.3.

Table 11 reports the results for the second-stage Fama-Macbeth regressions for carry and momentum portfolios. Note that, because we do not include a constant in the secondstage cross-sectional regressions, $R^{2}$ 's can become negative for badly fitted models. As widely recognized in the literature, the CAPM model fails to explain the cross section of carry or momentum returns with insignificant price of market risk and a low $R^{2}$. Consistent with Dobrynskaya (2014) and Dobrynskaya (2017), the price of downside risk is significantly negative in carry and momentum portfolios. The DR-CAPM explains a reasonable amount of the cross sectional variation for carry and momentum portfolios, with $R^{2}$ 's of $50 \%$ and $73 \%$, respectively.

It is not surprising that the FX model gives the best performance among all four models considered in pricing the carry portfolios, given the fact that the CARRY factor 
is constructed from carry portfolios themselves. However, CARRY fails to explain the cross section of momentum portfolios in our sample. The estimated price of CARRY in the momentum portfolios is significantly negative, as opposed to the positive value in the carry portfolios. In addition, the cross-section $R^{2}$ of the FX model is only $40 \%$ in the momentum regression.

Turning to our model with the dollar and global tail risk factors, the price of Tail is highly significant and negative in both carry and momentum portfolios. The negative sign of $\hat{\lambda}_{\text {tail }}$ is consistent with the tail-beta-sorted returns in Section 4.1, which has a significant negative sample mean. Compared with the regression using DOL alone (third column), adding the Global Tail factor increases the cross-section pricing performance greatly. Moreover, the univariate regressions using DOL yield an insignificant DOL risk premium and negative $R^{2}$ for both carry and momentum portfolios, indicating poor goodness of cross-sectional fit. Thus, the cross-sectional explanatory power of our model can be attributed almost exclusively to the Global Tail factor.

While there are many studies that manage to explain the cross section of carry and momentum portfolios separately, relatively fewer models successfully capture the joint cross section of carry and momentum portfolios. We further investigate the pricing performance of the Global Tail factor on the cross section of currency portfolios for multiple strategies. In particular, we consider the cross section of carry and momentum portfolios jointly. These regression results are reported in Table 12. Our model achieves the highest $R^{2}$ and the lowest RMSE in both portfolios among its competitors. Similar to the results in Table 11, the estimated risk premiums for Global Tail are negative and highly statistically significant. This is an important achievement of our model, as factors that are priced in portfolios sorted by a single characteristic do not necessarily explain joint portfolios. For instance, the FX model, which performs extremely well in pricing the carry portfolio, explains less than $20 \%$ when considering carry and momentum portfolios simultaneously.

Figure 3 shows scatter plots of realized mean excess returns against the modelpredicted excess returns for the cross section of carry and momentum portfolios. The 
failure of the CAPM is evident from the top-left panel of Figure 3, with all portfolios lying across a horizontal line. Portfolios lie around the 45 degree line in the top-right panel for the DR-CAPM specification with a few of outliers. While the carry portfolios line up nicely for the FX specification in the lower-left panel, the momentum portfolios are poorly aligned and even suggest a negative relation between fitted and realized excess returns. Among the four plots, portfolios lie closest to the 45 degree line in the lower-right panel, which corresponds to our model. Thus, our model delivers a better goodness of fit in the cross section of carry and momentum portfolios with visibly smallest pricing errors.

The estimation results in Table 11 and 12 show that the Global Tail risk carries a significant negative risk premium in the cross section of currency excess returns. This result can be interpreted intuitively as follows. Equity put returns are on average negative, which implies that investors are willing to pay a price to hedge against equity tail risk. Because currencies with positive betas can be used to hedge tail risk, these currencies are traded at a premium and earn less returns. On the contrary, currencies with negative betas should earn a tail risk premium.

\subsection{Cross-Sectional Asset Pricing with Control Factors}

The existing literature has managed to explain the cross section of currencies using risk factors, including those that may contain similar economic information as the Global Tail factor. In this section, we show that the explanatory power in the Global Tail factor is not attenuated by the inclusion of other risk factors previously used in the literature.

To assess the additional explanatory power of Global Tail for currency returns, we consider the following control risk factors: the carry trade risk factor (CARRY) in Lustig et al. (2011), the innovations in global FX volatility ( $\Delta$ FXvol) in Menkhoff et al. (2012a), the innovations in the index of global ex ante tail risk concerns ( $\Delta$ GRIX) in Gao et al. (2018), the dollar carry in Lustig et al. (2014), and the global Dollar in Verdelhan (2018). CARRY and $\triangle F X v o l$ are established factors shown to explain the cross-section of currency returns. $\Delta$ GRIX is the option-implied global tail risk concerns constructed across 
different asset classes, which shares similar economic information as our Global Tail factor. Since the Global Tail factors originates from the US equity market, it is interesting to see whether its explanatory power is subsumed by a US-specific currency factor. We therefore include the Dollar carry as a control variable, a factor which captures US-specific business cycle variations. Lastly, we also include the Global Dollar as a control variable. The Global Dollar is meant to capture the global aspect of the Dollar factor, which may have substitutionary or complementary information to our Global Tail factor.

Panel A in Table 13 reports the linear correlation coefficients between the control factors and the Global Tail factor. The correlation with the $\Delta$ GRIX factor, which is the factor with the most closely related economic interpretation, is as small as -0.04 for the Global Tail in the all-currencies case and -0.24 in the developed-market case. The reason might be that the $\Delta$ GRIX is constructed using multiple markets and not just equities. As illustrated in Section 2, our construction of the global tail factor also has advantages compared with the FX tail index in Gao et al. (2018). Correlations of the Global Tail factor with the Dollar Carry return are the largest in magnitude (-0.35 for all countries and -0.41 for the developed markets).

We run the Fama-Macbeth regression with the aforementioned factors as control variables, one at a time. Panel B in Table 13 shows the regression results with control factors, with the cross-section of carry and momentum portfolios as test assets. Each column corresponds to one Fama-Macbeth regression in which the "Control" factor is indicated in the first row of the column. Estimators for the Global Tail risk premium are negative and highly statistically significant in all cases, ranging from -0.02 to -0.03 , consistent with the regression results without control variables in Table 12.

The regression with CARRY as an additional factor explains the highest variation in the cross section of carry and momentum portfolios, with an $R^{2}$ of $93 \%$. Despite its statistical significance, the price of risk for CARRY drops from 0.01, the estimate without the Global Tail factor in Table 12, to 0.006 in the presence of the Global Tail. Moreover, The FX model with DOL and CARRY delivers a cross sectional $R^{2}$ of $32 \%$ in Table 12 , which increases to $93 \%$ after adding the Global Tail factor. Other control factors are not 
significant except for the Global Dollar factor. Nevertheless, the negative sign of the price of Global Dollar risk is not consistent with Verdelhan (2018) and should be interpreted with caution.

\section{Conclusion}

This paper studies the pricing of US equity tail risk in the cross section of currency returns. We find that the US tail risk factor bears a negative price of risk: Currencies with higher exposure to US tail risk have significantly lower return than currencies with lower exposure to this factor. In a reduced-form model, we show that the US tail risk factor is priced in the cross section of currency returns only when it has a global component. We also show that the return of a portfolio that buys high tail beta currencies and shorts low tail beta currencies can isolate the global component of the US tail risk factor. We refer to this return spread as Global Tail risk. Empirically, this global factor can explain a large portion of the cross section of carry and momentum returns and outperform other popular models. 


\section{References}

Aït-Sahalia, Y., Cacho-Diaz, J., Laeven, R. J., 2015. Modeling financial contagion using mutually exciting jump processes. Journal of Financial Economics 117, 585-606.

Akram, Q. F., Rime, D., Sarno, L., 2008. Arbitrage in the foreign exchange market: Turning on the microscope. Journal of International Economics 76, 237-253.

Andersen, T. G., Bondarenko, O., Todorov, V., Tauchen, G., 2015. The fine structure of equity-index option dynamics. Journal of Econometrics 187, 532-546.

Backus, D. K., Foresi, S., Telmer, C. I., 2001. Affine term structure models and the forward premium anomaly. The Journal of Finance 56, 279-304.

Bakshi, G., Panayotov, G., 2013. Predictability of currency carry trades and asset pricing implications. Journal of Financial Economics 110, 139-163.

Bekaert, G., Panayotov, G., 2019. Good carry, bad carry. Working Paper .

Bollerslev, T., Marrone, J., Xu, L., Zhou, H., 2014. Stock return predictability and variance risk premia: Statistical inference and international evidence. Journal of Financial and Quantitative Analysis 49, 633-661.

Bollerslev, T., Todorov, V., 2011. Tails, fears, and risk premia. The Journal of Finance $66,2165-2211$.

Brunnermeier, M. K., Nagel, S., Pedersen, L. H., 2008. Carry trades and currency crashes. NBER Macroeconomics Annual 23, 313-348.

Burnside, C., Eichenbaum, M., Kleshchelski, I., Rebelo, S., 2011. Do peso problems explain the returns to the carry trade? Review of Financial Studies 24, 853-891.

Chernov, M., Graveline, J., Zviadadze, I., 2018. Crash risk in currency returns. Journal of Financial and Quantitative Analysis 53, 1-34. 
Colacito, R., Croce, M. M., Gavazzoni, F., Ready, R., 2018. Currency risk factors in a recursive multicountry economy. The Journal of Finance 73, 2719-2756.

Daniel, K., Hodrick, R. J., Lu, Z., et al., 2017. The carry trade: Risks and drawdowns. Critical Finance Review 6, 211-262.

Della Corte, P., Riddiough, S. J., Sarno, L., 2016. Currency premia and global imbalances. The Review of Financial Studies 29, 2161-2193.

Dobrynskaya, V., 2014. Downside market risk of carry trades. Review of Finance 18, $1885-1913$.

Dobrynskaya, V., 2017. Upside and downside risks in momentum returns, working paper.

Farhi, E., Fraiberger, S. P., Gabaix, X., Ranciere, R., Verdelhan, A., 2015. Crash risk in currency markets. Working paper .

Farhi, E., Gabaix, X., 2015. Rare disasters and exchange rates. The Quarterly Journal of Economics 131, 1-52.

Filippou, I., Gozluklu, A. E., Taylor, M. P., 2018. Global political risk and currency momentum. Journal of Financial and Quantitative Analysis 53, 2227-2259.

Filippou, I., Taylor, M. P., 2017. Common macro factors and currency premia. Journal of Financial and Quantitative Analysis 52, 1731-1763.

Gao, G. P., Lu, X., Song, Z., 2018. Tail risk concerns everywhere. Management Science, forthcoming .

Hau, H., Rey, H., 2006. Exchange rates, equity prices, and capital flows. The Review of Financial Studies 19, 273-317.

Jurek, J. W., 2014. Crash-neutral currency carry trades. Journal of Financial Economics $113,325-347$. 
Lee, S. S., Wang, M., 2018. The impact of jumps on carry trade returns. Journal of Financial Economics 131, 433-455.

Lettau, M., Maggiori, M., Weber, M., 2014. Conditional risk premia in currency markets and other asset classes. Journal of Financial Economics 114, 197-225.

Londono, J., 2015. The variance risk premium around the world. Unpublished working paper. Federal Reserve Board, Washington D.C.

Londono, J. M., Zhou, H., 2017. Variance risk premiums and the forward premium puzzle. Journal of Financial Economics 124, 415-440.

Lu, Z., Murray, S., 2018. Bear beta. Journal of Financial Economics, forthcoming .

Lustig, H., Roussanov, N., Verdelhan, A., 2011. Common risk factors in currency markets. Review of Financial Studies 11, 3731-3777.

Lustig, H., Roussanov, N., Verdelhan, A., 2014. Countercyclical currency risk premia. Journal of Financial Economics 111, 527-553.

Lustig, H., Verdelhan, A., 2007. The cross section of foreign currency risk premia and consumption growth risk. The American Economic Review 101, 3477-3500.

Menkhoff, L., Sarno, L., Schmeling, M., Schrimpf, A., 2012a. Carry trades and global foreign exchange volatility. The Journal of Finance 67, 681-718.

Menkhoff, L., Sarno, L., Schmeling, M., Schrimpf, A., 2012b. Currency momentum strategies. Journal of Financial Economics 106, 660-684.

Newey, W. K., West, K. D., 1987. Hypothesis testing with efficient method of moments estimation. International Economic Review 28, 777-787.

Rafferty, B., 2012. Currency returns, skewness and crash risk, working paper.

Rapach, D. E., Strauss, J. K., Zhou, G., 2013. International stock return predictability: what is the role of the united states? The Journal of Finance 68, 1633-1662. 
Verdelhan, A., 2018. The share of systematic variation in bilateral exchange rates. The Journal of Finance 73, 375-418.

Wachter, J. A., 2013. Can time-varying risk of rare disasters explain aggregate stock market volatility? The Journal of Finance 68, 987-1035.

Wongswan, J., 2009. The response of global equity indexes to us monetary policy announcements. Journal of International Money and Finance 28, 344-365. 
Figure 1: Time Series of S\&P 500 Returns and the US Equity Tail Risk Factor A. S\&P 500 Index Return

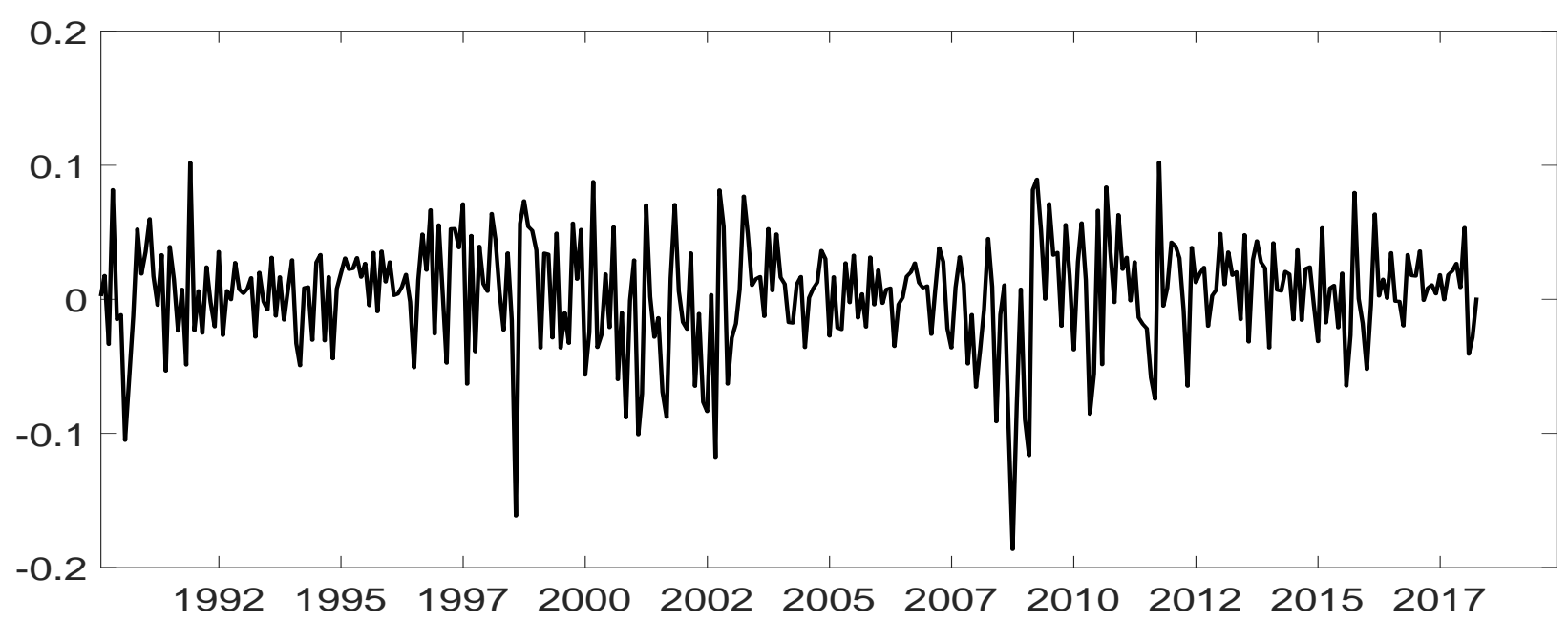

B. US Equity Tail Risk

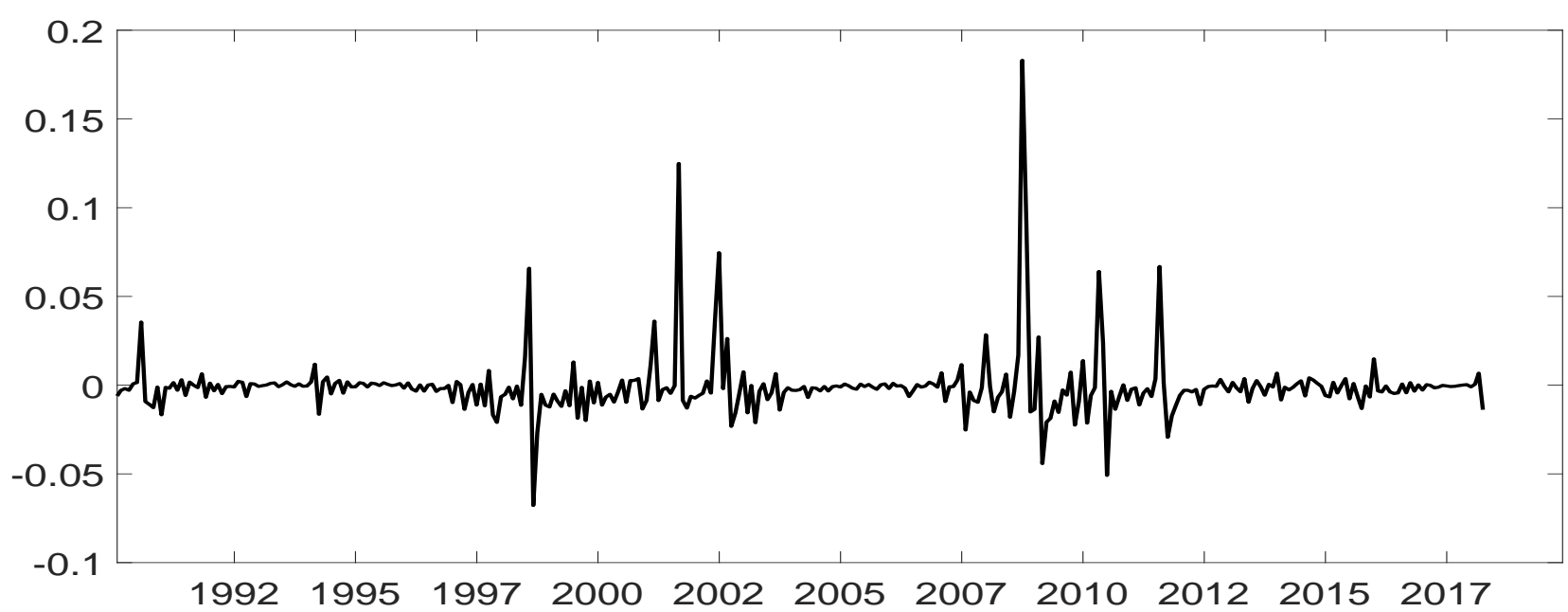

This figure shows time series of S\&P 500 index returns and the US equity tail risk factor from February 1990 to April 2018 in Panels A and Panel B, respectively. The tail factor is calculated as the difference between the logarithm change of CBOE Put Protection index (PPUT) and the logarithm change of the S\&P 500 index. The PPUT index is constructed by CBOE to track the performance of a hypothetical strategy that holds a long position indexed to S\&P 500 and buys a monthly $5 \%$ out-of-the-money S\&P 500 index put option. The strike of the put option selected is the first available strike below $95 \%$ of the last disseminated value of the S\&P 500 index. 
Figure 2: Time Series Betas of the Five Tail-beta-sorted Portfolios

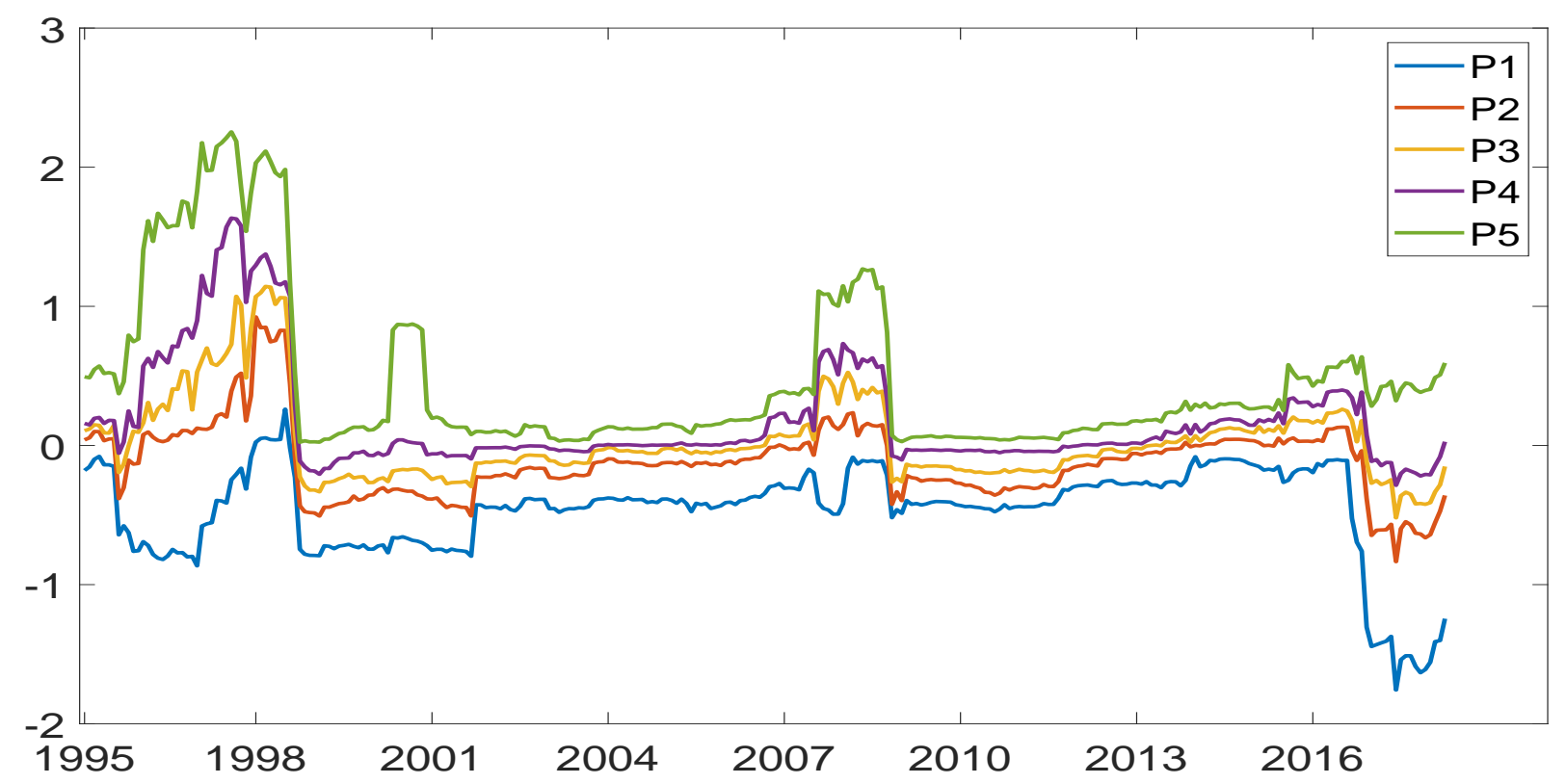

This figure shows the time series of the tail betas for the five tail-beta-sorted currency portfolios. The tail betas are estimated using the following regression: $r x_{i, t}=\alpha_{i}+\beta_{m, i} r_{m, t}+\beta_{\text {Tail }, i}$ Tail $_{t}+\varepsilon_{i, t}$, where $r x_{i, t}$ is the excess return of currency $i$ over month $t, r_{m, t}$ is the return of the S\&P 500 index over the same period, and Tail is the US equity tail factor (see figure 1). The regressions are estimated using 60 -month rolling windows in the pre-formation period. The sample period runs from February 1995 to April 2018. 
Figure 3: Currency Portfolio Returns, Cross-sectional Model Performances
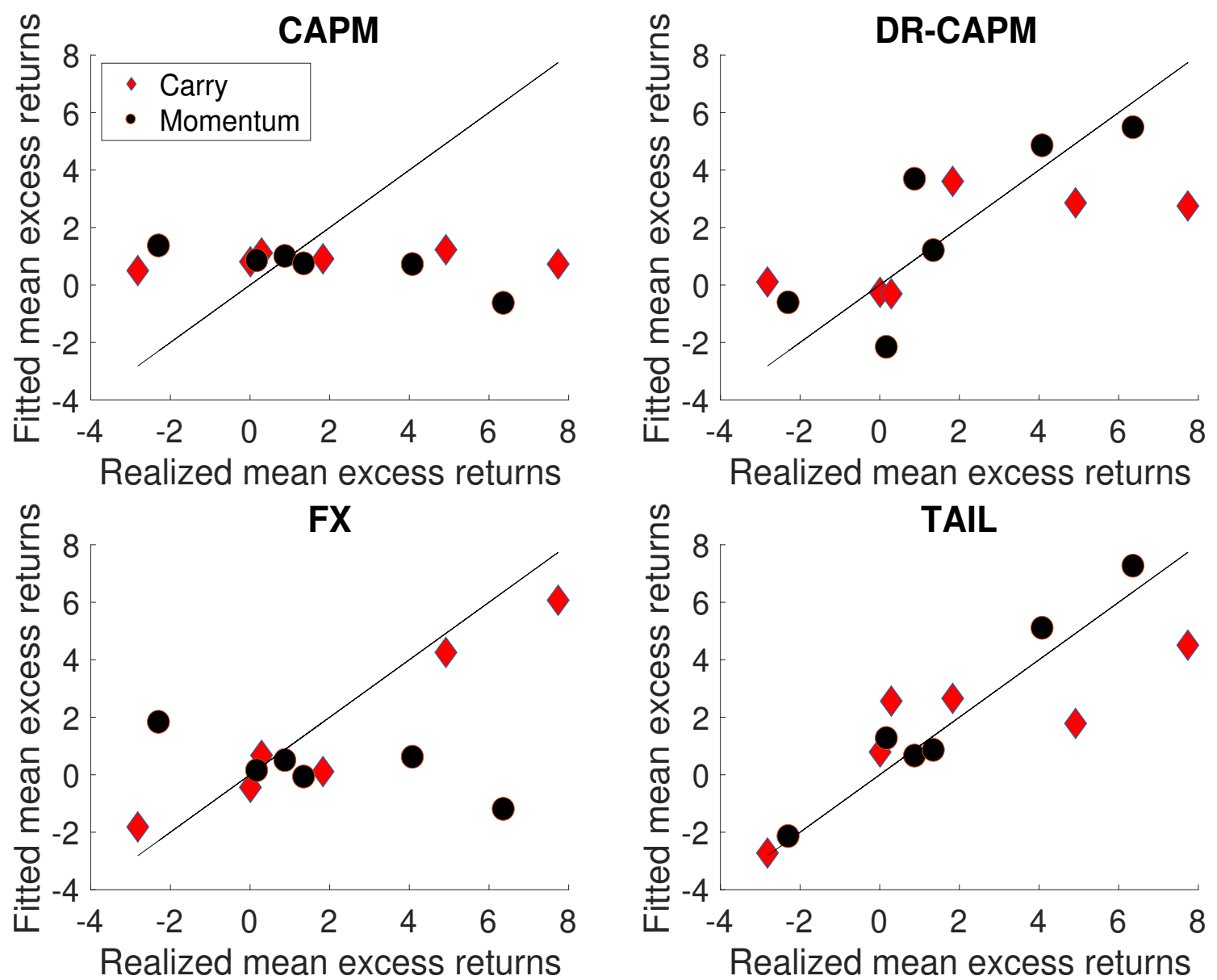

This figure shows scattered plots of realized annualized mean excess returns against the fitted excess returns, in percent, for the following models: the unconditional capital asset pricing model (CAPM) in the upper left panel, the downside risk CAPM (DR-CAPM) in the upper right panel, the FX factor model (FX) in the lower left panel, and our model (Tail) in the lower right panel. Test assets are the cross section of carry (the red diamonds) and momentum (the black dots) portfolios. For each portfolio style, we also include the return of the H-L portfolio. The sample period runs from February 1995 to April 2018. 
Table 1: Summary Statistics

\begin{tabular}{|c|c|c|c|c|c|c|}
\hline \multicolumn{7}{|c|}{ Panel A: Summary Statistics (in percent) } \\
\hline & Tail & MKT & $\Delta \mathrm{VIX}$ & DOL & CARRY & $\Delta \mathrm{FXvol}$ \\
\hline Mean & -0.09 & 0.39 & -0.36 & 0.11 & 0.78 & -0.05 \\
\hline $\mathrm{SD}$ & 1.79 & 4.11 & 18.32 & 1.99 & 2.54 & 9.96 \\
\hline Skew & 5.03 & -0.80 & 0.55 & -0.61 & -0.38 & 0.96 \\
\hline Kurt & 45.59 & 4.88 & 4.46 & 4.60 & 4.34 & 7.67 \\
\hline Q5 & -6.78 & -18.66 & -48.60 & -7.85 & -8.61 & -34.39 \\
\hline Q95 & -3.35 & -11.69 & -40.11 & -6.25 & -6.59 & -24.08 \\
\hline $\mathrm{AC}$ & 0.18 & 0.05 & -0.19 & 0.13 & 0.21 & -0.31 \\
\hline
\end{tabular}

Panel B: Correlation Matrix

\begin{tabular}{lrrrrrr}
\hline & Tail & MKT & $\Delta$ VIX & DOL & CARRY & $\Delta$ FXvol \\
\hline Tail & 1 & -0.61 & 0.43 & -0.29 & -0.16 & 0.18 \\
MKT & & 1 & -0.64 & 0.33 & 0.21 & -0.19 \\
$\Delta$ VIX & & & 1 & -0.21 & -0.22 & 0.22 \\
DOL & & & & 1 & 0.34 & -0.21 \\
CARRY & & & & & 1 & -0.34 \\
$\Delta$ FXvol & & & & & & 1 \\
\hline
\end{tabular}

This table reports summary statistics (Panel A) and the correlation matrix (Panel B) for a set of monthly US equity- and currency-related factors. Summary statistics include mean, standard errors (SD), skewness (Skew), Kurtosis (Kurt), 5th percentile (Q5), 95th percentile (Q95), and first order autocorrelation coefficient (AC). The tail factor (TAIL) is calculated as the difference between the log change of CBOE Put Protection index (PPUT) and the log change of the S\&P 500 index. The PPUT index is constructed by CBOE to track the performance of a hypothetical strategy that holds a long position indexed to S\&P 500 and buys a monthly $5 \%$ out-of-the-money S\&P 500 index put option. The strike of the put option selected is the first available strike below $95 \%$ of the last disseminated value of the $\mathrm{S} \& \mathrm{P} 500$ index. MKT is the excess return of the $\mathrm{S} \& \mathrm{P} 500$ index, which is calculated as $\mathrm{MKT}_{t}=\log \left(\mathrm{SPX}_{t}\right)-\log \left(\mathrm{SPX}_{t-1}\right)-i_{t-1}$, where $S P X_{t}$ is the time- $t$ price of the index and $i_{t-1}$ is the continuous compounded risk free rate effective from $t-1$ to $t$. $\Delta$ VIX is the log change of the CBOE VIX index. DOL is the dollar risk factor in Lustig et al. (2011), which is calculated as the average excess return of a set of foreign currency portfolios. CARRY is the carry trade risk factor in Lustig et al. (2011), which is calculated as the high minus low return spread of the currency portfolios sorted by forward discount. $\triangle \mathrm{FXvol}$ is the logarithm change of volatility in the foreign exchange market, constructed following Menkhoff et al. (2012a). The sample runs from January 1990 to April 2018. 
Table 2: Tail-beta-sorted Currency Portfolios (US Investor)

\begin{tabular}{llllllll}
\hline \multicolumn{2}{l}{ Panel A: All Currencies } & & & & \\
\hline Portfolio & 1 & 2 & 3 & 4 & 5 & Average & H-L \\
\hline Mean & 2.37 & 1.56 & 0.04 & -0.48 & -1.24 & 0.45 & $-3.61^{* * *}$ \\
& $(1.40)$ & $(0.95)$ & $(0.02)$ & $(-0.37)$ & $(-0.84)$ & $(0.33)$ & $(-2.60)$ \\
Std. Dev. & 8.17 & 7.93 & 8.60 & 6.23 & 7.13 & 6.49 & 6.70 \\
Skew & -0.34 & -0.34 & -0.85 & 0.34 & -0.82 & -0.45 & 0.29 \\
Kurt & 4.60 & 5.35 & 7.45 & 8.28 & 5.44 & 4.56 & 4.74 \\
SR & 0.29 & 0.20 & 0.00 & -0.08 & -0.17 & 0.07 & -0.54 \\
AC & 0.11 & -0.04 & 0.06 & 0.05 & 0.14 & 0.07 & 0.06 \\
FX return & -0.58 & -0.18 & -1.38 & -1.23 & -2.45 & -1.17 & -1.87 \\
Pre- $\beta$ & -0.46 & -0.12 & 0.03 & 0.18 & 0.46 & 0.02 & 0.93 \\
Pre-FD & 2.93 & 1.74 & 1.41 & 0.73 & 1.31 & 1.63 & -1.62 \\
Post-FD & 2.91 & 1.82 & 1.37 & 0.74 & 1.27 & 1.62 & -1.65 \\
RX(-1,0) & 2.07 & 1.62 & 1.15 & -0.96 & -0.96 & 0.58 & -3.03 \\
\hline
\end{tabular}

Panel B: Developed Markets' Currencies

\begin{tabular}{llllllll}
\hline Portfolio & 1 & 2 & 3 & 4 & 5 & Average & H-L \\
\hline Mean & $3.46^{* *}$ & -0.33 & -0.06 & -0.47 & -2.68 & -0.02 & $-6.13^{* * *}$ \\
& $(1.99)$ & $(-0.18)$ & $(-0.03)$ & $(-0.27)$ & $(-1.65)$ & $(-0.01)$ & $(-3.64)$ \\
Std. Dev. & 8.37 & 8.60 & 8.31 & 8.48 & 7.81 & 7.04 & 8.12 \\
Skew & -0.10 & -0.20 & 0.14 & 0.14 & -1.07 & -0.15 & -0.52 \\
Kurt & 3.67 & 4.76 & 4.97 & 5.38 & 9.35 & 4.07 & 6.15 \\
SR & 0.41 & -0.04 & -0.01 & -0.06 & -0.34 & 0.00 & -0.76 \\
AC & 0.03 & 0.05 & -0.04 & -0.05 & 0.13 & 0.04 & 0.03 \\
FX return & 2.32 & -0.31 & 0.28 & 0.15 & -2.32 & 0.02 & -4.65 \\
Pre-beta & -0.49 & -0.16 & 0.02 & 0.17 & 0.44 & 0.00 & 0.93 \\
Pre-FD & 1.14 & -0.02 & -0.38 & -0.61 & -0.30 & -0.03 & -1.43 \\
Post-FD & 1.16 & -0.05 & -0.38 & -0.57 & -0.32 & -0.03 & -1.48 \\
RX(-1,0) & 2.97 & -0.05 & -0.25 & -1.03 & -1.62 & 0.00 & -4.59 \\
\hline
\end{tabular}

This table reports excess returns of the tail-beta-sorted portfolios for all currencies (Panel A) and for the subsample of currencies from developed markets (Panel B) from the point of view of a US investor. We first estimate $\beta_{\text {Tail }, i}$ for each currency $i$ in the regression in Equation (7) using a rolling window of 60 months. Then, we sort currencies into five portfolios based on their estimated $\beta_{\text {Tail }, i}$. For each portfolio $j(\mathrm{j}=1, \ldots, 5$, Average, and H-L), we report the mean excess return in the next month and its corresponding t-statistic (in parenthesis), standard deviation (Std. Dev), skewness, kurtosis, the Sharpe ratio (SR), the first-order autocorrelation coefficient (AC), the mean return of the spot exchange rate (FX return), the pre-formation forward discount (Pre-FD), the post-formation forward discount (PostFD), the pre-formation $\beta_{\text {Tail }, i}$ (Pre- $\beta$ ), and the excess return in the pre-formation period $(R X(-1,0))$. All moments are annualized and reported in percentage points. ${ }^{*},{ }^{* *}$, and $* * *$ represent $10 \%, 5 \%$, and $1 \%$ significangg levels. The sample period runs from February 1995 to April 2018. 
Table 3: Top 10 Currencies in Tail-beta-sorted Portfolios 1 and 5

\begin{tabular}{lllc|llll}
\hline \multicolumn{3}{c|}{ Panel A: All Countries } & \multicolumn{3}{c}{ Panel B: Developed Markets } \\
\hline \multicolumn{1}{c}{ P1 P5 } & \multicolumn{2}{c|}{ P1 } & \multicolumn{3}{c}{ P5 } \\
Country & Freq. & Country & Freq. & Country & Freq. & Country & Freq. \\
\hline South Africa & 0.57 & UK & 0.42 & Australia & 0.53 & UK & 0.44 \\
Australia & 0.55 & Japan & 0.39 & New Zealand & 0.43 & Japan & 0.41 \\
New Zealand & 0.43 & Malaysia & 0.39 & Norway & 0.33 & Hong Kong & 0.31 \\
Norway & 0.34 & India & 0.31 & Japan & 0.25 & Switzerland & 0.28 \\
Canada & 0.30 & Russia & 0.30 & Canada & 0.24 & Singapore & 0.27 \\
Japan & 0.26 & Thailand & 0.27 & UK & 0.23 & New Zealand & 0.14 \\
UK & 0.22 & Switzerland & 0.27 & Czech & 0.19 & Czech & 0.14 \\
Iceland & 0.22 & Saudi Arabia & 0.23 & Israel & 0.11 & Sweden & 0.13 \\
Mexico & 0.21 & Hungary & 0.19 & Sweden & 0.10 & Norway & 0.12 \\
Indonesia & 0.20 & Mexico & 0.19 & Switzerland & 0.10 & South Korea & 0.11 \\
\hline
\end{tabular}

This table reports the top 10 currencies most often included in portfolios 1 (P1) and 5 (P5) in Table 2. Panel A shows results for the full sample of currencies, while Panel B shows results for a subsample with only currencies from developed markets. We report the ranked currencies along with its frequency (as a fraction of total months) appeared in the portfolios. The sample runs from February 1995 to April 2018. 
Table 4: Tail-beta-sorted Currency Portfolios (UK investor)

\begin{tabular}{llllllll}
\hline \multicolumn{2}{l}{ Panel A: All Currencies } & \multicolumn{1}{c}{ A } & \multicolumn{1}{c}{ Average } & H-L \\
\hline Portfolio & \multicolumn{1}{c}{1} & \multicolumn{1}{c}{2} & \multicolumn{1}{c}{3} & \multicolumn{1}{c}{5} & \multicolumn{1}{c}{ A } \\
\hline Mean & 2.36 & 1.85 & -0.07 & -0.70 & -1.59 & 0.37 & $-3.95^{* * *}$ \\
& $(1.33)$ & $(1.09)$ & $(-0.04)$ & $(-0.45)$ & $(-0.90)$ & $(0.25)$ & $(-2.63)$ \\
Std. Dev. & 8.58 & 8.20 & 8.28 & 7.54 & 8.49 & 7.20 & 7.24 \\
Skew & 0.10 & 0.85 & 0.75 & 0.41 & 0.47 & 0.81 & 0.21 \\
Kurt & 5.30 & 8.39 & 9.81 & 4.87 & 4.93 & 7.59 & 4.41 \\
SR & 0.28 & 0.23 & -0.01 & -0.09 & -0.19 & 0.05 & -0.55 \\
AC & -0.05 & -0.13 & -0.12 & -0.06 & -0.04 & -0.11 & 0.08 \\
Pre-FD & 2.23 & 0.96 & 0.39 & 0.23 & 0.61 & 0.89 & -1.62 \\
Post-FD & 2.21 & 0.97 & 0.49 & 0.13 & 0.60 & 0.88 & -1.61 \\
Pre- $\beta$ & -0.64 & -0.32 & -0.14 & 0.05 & 0.32 & -0.15 & 0.96 \\
FX return & 0.11 & 0.87 & -0.56 & -0.84 & -2.12 & -0.51 & -2.23 \\
\hline
\end{tabular}

Panel B: Developed Markets' Currencies

\begin{tabular}{llllclll}
\hline Portfolio & \multicolumn{1}{c}{1} & \multicolumn{1}{c}{2} & \multicolumn{1}{c}{3} & \multicolumn{1}{c}{4} & \multicolumn{1}{c}{5} & Average & H-L \\
\hline Mean & $3.33^{*}$ & 0.20 & -0.86 & -0.19 & -3.05 & -0.11 & $-6.38^{* * *}$ \\
& $(1.83)$ & $(0.11)$ & $(-0.49)$ & $(-0.11)$ & $(-1.81)$ & $(-0.08)$ & $(-3.53)$ \\
Std. Dev. & 8.79 & 8.58 & 8.47 & 8.39 & 8.11 & 7.14 & 8.72 \\
Skew & 0.55 & 1.16 & 0.76 & 0.81 & 0.52 & 1.10 & -0.18 \\
Kurt & 4.72 & 11.47 & 7.38 & 6.99 & 5.03 & 9.29 & 5.72 \\
SR & 0.38 & 0.02 & -0.10 & -0.02 & -0.38 & -0.02 & -0.73 \\
AC & -0.02 & -0.11 & -0.13 & -0.14 & 0.00 & -0.11 & 0.04 \\
Pre-FD & 0.57 & -0.66 & -0.96 & -1.25 & -1.43 & -0.74 & -2.00 \\
Post-FD & 0.60 & -0.67 & -0.97 & -1.22 & -1.46 & -0.75 & -2.06 \\
Pre- $\beta$ & -0.64 & -0.31 & -0.16 & -0.01 & 0.22 & -0.18 & 0.86 \\
FX return & 2.76 & 0.84 & 0.06 & 1.08 & -1.56 & 0.63 & -4.32 \\
\hline
\end{tabular}

This table reports excess returns of the tail-beta-sorted portfolios for all currencies (Panel A) and for the subsample of currencies from developed markets (Panel B) from the point of view of a UK investor (that is, when the UK pound is the reference currency). We first estimate $\beta_{\text {Tail, } i}$ for each currency $i$ in the regression in equation (7) using a rolling window of 60 months. Then, we sort currencies into five portfolios based on their estimated $\beta_{\text {Tail }, i}$. For each portfolio $j(\mathrm{j}=1, \ldots, 5$, Average, and $\mathrm{H}-\mathrm{L})$, we report the mean excess return in the next month and its corresponding the t-statistic (in parenthesis), standard deviation (Std. Dev), skewness, kurtosis, the Sharpe ratio (SR), the first-order autocorrelation coefficient (AC), the mean return of the spot exchange rate (FX return), the pre-formation forward discount (Pre-FD), the post-formation forward discount (Post-FD), the pre-formation $\beta_{\text {Tail }, i}$ (Pre- $\beta$ ), and the excess return in the pre-formation period $(R X(-1,0)) .{ }^{*},{ }^{* *}$, and ${ }^{* * *}$ represent $10 \%, 5 \%$, and $1 \%$ significance levels. All moments are annualized and reported in percentage points. The sample period runs from February 1995 to April 2018. 
Table 5: Tail-beta-sorted Currency Portfolios (Japanese investor)

\begin{tabular}{|c|c|c|c|c|c|c|c|}
\hline \multicolumn{8}{|c|}{ Panel A: All Currencies } \\
\hline Portfolio & 1 & 2 & 3 & 4 & 5 & Average & H-L \\
\hline Mean & $\begin{array}{l}5.75^{* *} \\
(2.38)\end{array}$ & $\begin{array}{l}4.68^{*} \\
(1.92)\end{array}$ & $\begin{array}{l}2.92 \\
(1.24)\end{array}$ & $\begin{array}{l}2.66 \\
(1.20)\end{array}$ & $\begin{array}{l}1.61 \\
(0.73)\end{array}$ & $\begin{array}{l}3.52 \\
(1.62)\end{array}$ & $\begin{array}{l}-4.14^{* * *} \\
(-2.80)\end{array}$ \\
\hline Std. Dev. & 11.63 & 11.74 & 11.36 & 10.63 & 10.62 & 10.49 & 7.12 \\
\hline Skew & -0.93 & -0.78 & -0.86 & -0.63 & -0.90 & -0.94 & 0.21 \\
\hline Kurt & 5.16 & 5.36 & 6.17 & 5.29 & 6.62 & 5.83 & 4.50 \\
\hline $\mathrm{SR}$ & 0.49 & 0.40 & 0.26 & 0.25 & 0.15 & 0.34 & -0.58 \\
\hline $\mathrm{AC}$ & -0.03 & 0.00 & 0.06 & 0.00 & 0.11 & 0.03 & 0.06 \\
\hline Pre-FD & 5.61 & 4.31 & 3.75 & 3.48 & 4.06 & 4.24 & -1.54 \\
\hline Post-FD & 5.60 & 4.32 & 3.84 & 3.38 & 4.00 & 4.23 & -1.60 \\
\hline Pre- $\beta$ & -0.45 & -0.12 & 0.06 & 0.24 & 0.52 & 0.05 & 0.97 \\
\hline FX return & 0.15 & 0.35 & -0.92 & -0.68 & -2.33 & -0.69 & -2.48 \\
\hline
\end{tabular}

Panel B: Developed Markets' Currencies

\begin{tabular}{llcccccc}
\hline Portfolio & \multicolumn{1}{c}{1} & \multicolumn{1}{c}{2} & \multicolumn{1}{c}{3} & \multicolumn{1}{c}{4} & \multicolumn{1}{c}{5} & Average & H-L \\
\hline Mean & $6.56^{* * *}$ & 3.08 & 2.89 & 2.72 & 0.26 & 3.10 & $-6.30^{* * *}$ \\
& $(2.71)$ & $(1.28)$ & $(1.17)$ & $(1.14)$ & $(0.12)$ & $(1.43)$ & $(-3.46)$ \\
Std. Dev. & 11.68 & 11.63 & 11.93 & 11.49 & 10.28 & 10.44 & 8.78 \\
Skew & -0.69 & -0.85 & -0.75 & -0.64 & -1.77 & -0.94 & -0.17 \\
Kurt & 4.76 & 6.01 & 4.95 & 5.20 & 13.68 & 5.77 & 5.59 \\
SR & 0.56 & 0.26 & 0.24 & 0.24 & 0.02 & 0.30 & -0.72 \\
AC & -0.01 & -0.01 & -0.03 & -0.01 & 0.13 & 0.01 & 0.04 \\
Pre-FD & 3.93 & 2.68 & 2.40 & 2.07 & 1.95 & 2.61 & -1.98 \\
Post-FD & 3.95 & 2.65 & 2.38 & 2.09 & 1.91 & 2.60 & -2.03 \\
Pre-beta & -0.44 & -0.11 & 0.05 & 0.19 & 0.44 & 0.03 & 0.88 \\
FX return & 2.65 & 0.41 & 0.48 & 0.69 & -1.61 & 0.52 & -4.26 \\
\hline
\end{tabular}

This table reports excess returns of the tail-beta-sorted portfolios for all currencies (Panel A) and for the subsample of currencies from developed markets (Panel B) from the point of view of a Japanese investor (that is, when the Japanese yen is the reference currency). We first

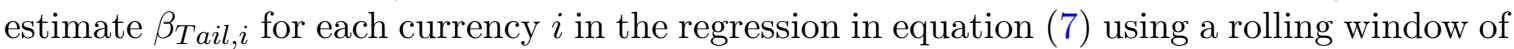
60 months. Then, we sort currencies into five portfolios based on their estimated $\beta_{\text {Tail }, i}$. For each portfolio $j(\mathrm{j}=1, \ldots, 5$, Average, and $\mathrm{H}-\mathrm{L})$, we report the mean excess return in the next month and its corresponding the t-statistics (in parenthesis), standard deviation (Std. Dev), skewness, kurtosis, the Sharpe ratio (SR), the first-order autocorrelation coefficient (AC), the mean return of the spot exchange rate (FX return), the pre-formation forward discount (Pre-FD), the post-formation forward discount (Post-FD), the pre-formation $\beta_{\text {Tail }, i}$ (Pre- $\beta$ ), and the excess return in the pre-formation period $(R X(-1,0)) .{ }^{*},{ }^{* *}$, and ${ }^{* * *}$ represent $10 \%, 5 \%$, and $1 \%$ significance levels. All moments are annualized and reported in percentage points. The sample period runs from February 1995 to April 2018. 
Table 6: Correlation Matrix of Global Tail for Different Base Currencies

\begin{tabular}{lllllll}
\hline & US & Japan & UK & US DM & JP DM & UK DM \\
\hline US & 1.00 & 0.88 & 0.89 & 0.57 & 0.52 & 0.52 \\
Japan & & 1.00 & 0.98 & 0.57 & 0.60 & 0.60 \\
UK & & & 1.00 & 0.58 & 0.59 & 0.60 \\
US DM & & & & 1.00 & 0.91 & 0.90 \\
JP DM & & & & & 1.00 & 0.98 \\
UK DM & & & & & & 1.00 \\
\hline
\end{tabular}

This table reports the correlation matrix of the Global Tail risk factor constructed from different base currencies. The Global Tail factor is the excess returns of the tail-beta-sorted portfolios for all currencies or for the currencies of developed markets (DM)from the point of view of a US, Japanese, or UK investor (that is, when the USD, JPY, or GBP is the reference currency, respectively). "US" ("Japan", "UK") represents the Global Tail risk factor constructed with all currencies against USD (JPY, GBP). "US DM", "JP DM", and "UK DM" are the corresponding counterparts constructed with only currencies of the developed markets. The sample period of each Global Tail factor runs from February 1995 to April 2018. 
Table 7: Time Series Regressions of the Tail-beta-sorted Currency Portfolios

\begin{tabular}{lllllll}
\hline \multicolumn{2}{l}{ Panel A: All Currencies } \\
\hline \multirow{2}{*}{$\alpha$} & P1 & P2 & P3 & P4 & P5 & P5-P1 \\
\cline { 2 - 7 } & 1.38 & 0.41 & -0.78 & -1.53 & $-2.05^{* *}$ & $-3.44^{* *}$ \\
DOL- $\beta$ & $(1.56)$ & $(0.47)$ & $(-0.83)$ & $(-1.78)$ & $(-2.38)$ & $(-2.50)$ \\
& $1.06^{* * *}$ & $1.01^{* * *}$ & $1.04^{* * *}$ & $0.73^{* * *}$ & $0.88^{* * *}$ & $-0.18^{* *}$ \\
$\Delta$ FXvol- $\beta$ & $(18.95)$ & $(17.63)$ & $(24.90)$ & $(14.89)$ & $(15.97)$ & $(-2.03)$ \\
& 1.41 & 0.95 & 0.17 & -1.20 & -0.41 & -1.82 \\
Adj. $R^{2}$ & $(1.55)$ & $(0.86)$ & $(0.21)$ & $(-1.27)$ & $(-0.37)$ & $(-1.17)$ \\
\hline
\end{tabular}

Panel B: Developed Markets

\begin{tabular}{lllllll}
\hline & $\mathrm{P} 1$ & $\mathrm{P} 2$ & $\mathrm{P} 3$ & $\mathrm{P} 4$ & $\mathrm{P} 5$ & $\mathrm{P} 5-\mathrm{P} 1$ \\
\cline { 2 - 7 }$\alpha$ & $2.45^{* *}$ & -1.48 & -1.01 & -1.67 & -3.69 *** & $-6.15^{* * *}$ \\
& $(2.21)$ & $(-1.52)$ & $(-1.07)$ & $(-1.71)$ & $(-3.30)$ & $(-3.60)$ \\
DOL- $\beta$ & $1.00^{* * *}$ & $1.08^{* * *}$ & $1.06^{* * *}$ & $1.07^{* * *}$ & $0.87^{* * *}$ & -0.13 \\
& $(14.62)$ & $(19.03)$ & $(18.68)$ & $(21.01)$ & $(11.11)$ & $(-1.09)$ \\
$\Delta$ FXvol- $\beta$ & $2.78^{*}$ & 0.27 & $2.15^{*}$ & 0.70 & 0.74 & -2.03 \\
& $(1.91)$ & $(0.25)$ & $(1.92)$ & $(0.66)$ & $(0.39)$ & $(-0.71)$ \\
Adj. $R^{2}$ & 0.60 & 0.70 & 0.70 & 0.69 & 0.54 & 0.01 \\
\hline
\end{tabular}

This table reports the time series regressions of the tail-beta-sorted currency portfolios for all currencies and for the developed markets, in panels A and B, respectively. The independent variables are the dollar risk factor (DOL) and the FX volatility $(\Delta \mathrm{FXvol})$. DOL is the average excess return of foreign currencies with respect to the US dollar and $\Delta F X v o l$ is innovation in aggregated FX volatility. We report regression coefficients along with their t-statistics (in parentheses) and adjusted $R^{2}$ 's. * , **, and *** represent $10 \%, 5 \%$, and $1 \%$ significance levels. The sample runs from February 1995 to April 2018. 
Table 8: Tail-beta-sorted Currency Portfolios (US investor, controlling for VIX)

\begin{tabular}{llllllll}
\hline \multicolumn{2}{l}{ Panel A: All Currencies } & \multicolumn{1}{c}{ Average } & H-L \\
\hline Portfolio & \multicolumn{1}{c}{1} & \multicolumn{1}{c}{2} & \multicolumn{1}{c}{3} & \multicolumn{1}{c}{4} & \multicolumn{1}{c}{5} & Aver \\
\hline Mean & 2.61 & 0.36 & 0.41 & -1.18 & -0.86 & 0.27 & $-3.48^{* *}$ \\
& $(1.50)$ & $(0.22)$ & $(0.25)$ & $(-1.03)$ & $(-0.56)$ & $(0.20)$ & $(-2.48)$ \\
Std. Dev. & 8.38 & 8.02 & 8.00 & 5.53 & 7.42 & 6.44 & 6.75 \\
Skew & -0.42 & -0.34 & -0.63 & -0.49 & -1.00 & -0.45 & 0.38 \\
Kurt & 4.90 & 5.43 & 5.98 & 5.07 & 6.52 & 4.60 & 6.15 \\
SR & 0.31 & 0.04 & 0.05 & -0.21 & -0.12 & 0.04 & -0.51 \\
AC & 0.09 & 0.02 & 0.05 & 0.01 & 0.15 & 0.07 & 0.09 \\
Pre-FD & 2.67 & 1.33 & 1.24 & 0.83 & 1.79 & 1.57 & -0.87 \\
Post-FD & 2.65 & 1.40 & 1.13 & 0.86 & 1.79 & 1.56 & -0.86 \\
Pre- $\beta$ & -0.50 & -0.17 & -0.03 & 0.11 & 0.39 & -0.04 & 0.89 \\
FX return & -0.07 & -0.89 & -0.83 & -2.00 & -2.71 & -1.30 & -2.64 \\
\hline
\end{tabular}

Panel B: Developed Markets' Currencies

\begin{tabular}{llllllll}
\hline Portfolio & \multicolumn{1}{c}{1} & \multicolumn{1}{c}{2} & \multicolumn{1}{c}{3} & \multicolumn{1}{c}{4} & \multicolumn{1}{c}{5} & Average & \multicolumn{1}{c}{ H-L } \\
\hline Mean & $3.05^{*}$ & -0.20 & -1.54 & 0.40 & -2.19 & -0.09 & $-5.24^{* * *}$ \\
& $(1.70)$ & $(-0.11)$ & $(-0.87)$ & $(0.25)$ & $(-1.36)$ & $(-0.06)$ & $(-3.17)$ \\
Std. Dev. & 8.68 & 8.43 & 8.53 & 7.92 & 7.74 & 7.03 & 7.98 \\
Skew & -0.23 & -0.04 & -0.18 & 0.22 & -1.17 & -0.17 & -0.16 \\
Kurt & 3.88 & 3.93 & 4.52 & 5.52 & 9.67 & 4.16 & 4.59 \\
SR & 0.35 & -0.02 & -0.18 & 0.05 & -0.28 & -0.01 & -0.66 \\
AC & 0.07 & -0.01 & 0.01 & -0.06 & 0.15 & 0.04 & 0.07 \\
Pre-FD & 1.01 & -0.18 & -0.51 & -0.37 & -0.05 & -0.02 & -1.06 \\
Post-FD & 1.02 & -0.17 & -0.51 & -0.37 & -0.05 & -0.02 & -1.07 \\
Pre-beta & -0.54 & -0.22 & -0.05 & 0.09 & 0.32 & -0.08 & 0.86 \\
FX return & 2.04 & -0.04 & -1.06 & 0.82 & -2.11 & -0.07 & -4.16 \\
\hline
\end{tabular}

This table reports excess returns of the tail-beta-sorted portfolios for all currencies (Panel A) and for the subsample of currencies from developed markets (Panel B) from the point of

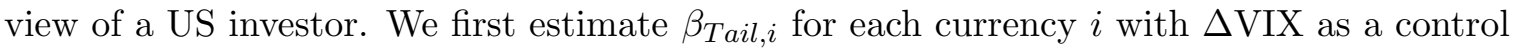
variable in the following regression: $r x_{i, t}=\alpha_{i}+\beta_{m, i} r_{m, t}+\beta_{T a i l, i} \operatorname{Tail}_{t}+\beta_{V I X, i} \Delta \operatorname{VIX}_{t}+\varepsilon_{i, t}$, where $r_{m, t}$ is the return of the $\mathbf{S} \mathbf{9 0 0}$ index, Tail is the tail factor described in table ??. We estimate this regression using a rolling window of 60 months. Then, we sort currencies into five portfolios based on their estimated $\beta_{\text {Tail }, i}$. For each portfolio $j(j=1, \ldots, 5$, Average, $\mathrm{H}-\mathrm{L}$ ), we report the mean excess return in the next month and its corresponding t-statistic (in parentheses), standard deviations (Std. Dev), skewness, kurtosis, Sharpe ratio (SR), autocorrelation coefficient (AC), pre-formation forward discount (Pre-FD), post-formation forward discount (Post-FD), pre-formation $\beta_{\text {Tail, } i}($ Pre- $\beta)$, and mean return of the spot exchange rate (FX return). ${ }^{*},{ }^{* *}$, and ${ }^{* * *}$ represent $10 \%, 5 \%$, and $1 \%$ significance levels. All moments are annualized and reported in percentage points. The sample period runs from February 1995 to April 2018. 
Table 9: Summary Statistics of Currency Carry and Momentum Portfolios

\begin{tabular}{|c|c|c|c|c|c|c|}
\hline Portfolio & 1 & 2 & 3 & 4 & 5 & H-L \\
\hline \multicolumn{7}{|c|}{ Panel A: Carry Portfolio - All Currencies } \\
\hline Excess Return & -2.11 & 0.35 & 1.70 & 1.85 & 4.46 & 6.57 \\
\hline Std. Dev & 6.50 & 6.26 & 6.66 & 9.15 & 9.98 & 8.66 \\
\hline Skew & -0.02 & 0.30 & -0.63 & -1.31 & -0.82 & -0.64 \\
\hline Kurt & 3.67 & 5.84 & 5.44 & 10.67 & 6.49 & 4.92 \\
\hline $\mathrm{SR}$ & -0.32 & 0.06 & 0.25 & 0.20 & 0.45 & 0.76 \\
\hline Corr $_{\text {Global Tail }}$ & -0.04 & -0.12 & -0.20 & -0.19 & -0.14 & -0.13 \\
\hline
\end{tabular}

Panel B: Momentum Portfolio - All Currencies

\begin{tabular}{lllllll}
\hline Excess Return & -2.76 & 0.59 & 2.18 & 2.22 & 4.85 & 7.62 \\
Std. Dev & 9.84 & 6.86 & 7.16 & 7.49 & 7.82 & 9.39 \\
Skew & -0.88 & -1.02 & -0.32 & -0.51 & 0.09 & 0.56 \\
Kurt & 9.37 & 8.11 & 5.20 & 6.65 & 5.90 & 8.57 \\
SR & -0.28 & 0.09 & 0.30 & 0.30 & 0.62 & 0.81 \\
Corr $_{\text {Global Tail }}$ & -0.08 & -0.16 & -0.13 & -0.15 & -0.23 & -0.11 \\
\hline
\end{tabular}

This table reports the excess returns of the carry and momentum portfolios in Panels A and $\mathrm{B}$, respectively, for all currencies in our sample. For each portfolio $j(j=1,2,3,4,5, H-L)$, we report the mean excess return, standard deviation (Std. Dev), skewness, kurtosis, and Sharpe ratio (SR). All moments are annualized and reported in percentage points. The carry portfolios are constructed by sorting currencies into five groups at time $t$ based on their forward discount at $t-1$. The momentum portfolios are constructed by sorting currencies into five groups at time $t$ based on their excess returns at $t-1$. The sample period runs January 1990 to April 2018. 
Table 10: Time Series Regression of the Carry and Momentum Portfolios

\begin{tabular}{|c|c|c|c|c|c|c|}
\hline & 1 & 2 & 3 & 4 & 5 & $\mathrm{H}-\mathrm{L}$ \\
\hline \multicolumn{7}{|c|}{ Panel A: Carry Portfolios } \\
\hline Intercept & $\begin{array}{l}-3.18^{* * *} \\
(-4.05)\end{array}$ & $\begin{array}{l}-0.70 \\
(-1.18)\end{array}$ & $\begin{array}{l}0.82 \\
(1.21)\end{array}$ & $\begin{array}{l}-0.77 \\
(-1.02)\end{array}$ & $\begin{array}{l}3.82^{* * *} \\
(3.47)\end{array}$ & $\begin{array}{l}7.00^{* * *} \\
(4.27)\end{array}$ \\
\hline Dol- $\beta$ & $\begin{array}{l}0.86^{* * *} \\
(19.44)\end{array}$ & $\begin{array}{l}0.84^{* * *} \\
(25.18)\end{array}$ & $\begin{array}{l}0.99^{* * *} \\
(24.56)\end{array}$ & $\begin{array}{l}1.08^{* * *} \\
(19.44)\end{array}$ & $\begin{array}{l}1.23^{* * *} \\
(19.00)\end{array}$ & $\begin{array}{l}0.36^{* * *} \\
(3.89)\end{array}$ \\
\hline Global Tail- $\beta$ & $\begin{array}{l}0.10^{* * *} \\
(2.56)\end{array}$ & $\begin{array}{l}0.00 \\
(0.06)\end{array}$ & $\begin{array}{l}-0.05 \\
(-1.48)\end{array}$ & $\begin{array}{l}-0.04 \\
(-1.11)\end{array}$ & $\begin{array}{l}-0.02 \\
(-0.26)\end{array}$ & $\begin{array}{l}-0.12 \\
(-1.34)\end{array}$ \\
\hline $\operatorname{Adj} R^{2}$ & 0.71 & 0.80 & 0.81 & 0.80 & 0.71 & 0.10 \\
\hline
\end{tabular}

Panel B: Momentum Portfolios

\begin{tabular}{lllllll}
\hline Intercept & $-3.31^{* *}$ & -0.85 & -0.12 & 0.34 & $2.66^{* * *}$ & $5.97^{* * *}$ \\
& $(-2.43)$ & $(-1.16)$ & $(-0.15)$ & $(0.36)$ & $(2.62)$ & $(3.03)$ \\
Dol- $\beta$ & $1.23^{* * *}$ & $0.91^{* * *}$ & $0.94^{* * *}$ & $0.94^{* * *}$ & $0.89^{* * *}$ & $-0.34^{* * *}$ \\
& $(15.43)$ & $(16.89)$ & $(17.35)$ & $(14.32)$ & $(13.38)$ & $(-2.73)$ \\
Global Tail- $\beta$ & 0.07 & -0.02 & -0.01 & -0.01 & $-0.14^{* *}$ & $-0.21^{* *}$ \\
& $(0.93)$ & $(-0.62)$ & $(-0.14)$ & $(-0.18)$ & $(-2.51)$ & $(-1.96)$ \\
Adj $R^{2}$ & 0.64 & 0.76 & 0.73 & 0.69 & 0.59 & 0.06 \\
\hline
\end{tabular}

This table reports time series regression results for carry and momentum portfolios in Panels $\mathrm{A}$ and $\mathrm{B}$, respectively. The independent variables are the dollar risk factor and the Global Tail risk factor, which is constructed from the long-short tail beta sorted currency portfolios. We report regression coefficients, t-statistics for standard deviations adjusted by Newey and West (1987) with 12 lags (in parentheses), and adjusted $R^{2}$ s. * ${ }^{* *}$, and ${ }^{* * *}$ represent $10 \%$, 5\%, and 1\% significance levels. The sample runs from January 1990 to April 2018. 
Table 11: Cross-section Asset Pricing Results of Carry and Momentum Portfolios

\begin{tabular}{|c|c|c|c|c|c|c|c|c|c|c|}
\hline & \multicolumn{5}{|c|}{ Carry } & \multicolumn{5}{|c|}{ Momentum } \\
\hline & CAPM & $\begin{array}{c}\text { DR- } \\
\text { CAPM }\end{array}$ & DOL & FX & $\begin{array}{c}\text { Global } \\
\text { Tail }\end{array}$ & CAPM & $\begin{array}{c}\text { DR- } \\
\text { CAPM }\end{array}$ & DOL & FX & $\begin{array}{c}\text { Global } \\
\text { Tail }\end{array}$ \\
\hline $\mathrm{MKT}$ & $\begin{array}{l}0.01 \\
(1.48)\end{array}$ & $\begin{array}{l}0.00 \\
(-0.39)\end{array}$ & & & & $\begin{array}{l}0.00 \\
(-0.29)\end{array}$ & $\begin{array}{l}0.00 \\
(-0.77)\end{array}$ & & & \\
\hline DR & & $\begin{array}{l}-0.04^{* * *} \\
(-3.75)\end{array}$ & & & & & $\begin{array}{l}-0.02^{* * *} \\
(-3.40)\end{array}$ & & & \\
\hline $\mathrm{DOL}$ & & & $\begin{array}{l}0.00 \\
(1.06)\end{array}$ & $\begin{array}{l}0.00 \\
(0.54)\end{array}$ & $\begin{array}{l}0.00 \\
(0.69)\end{array}$ & & & $\begin{array}{l}0.00 \\
(0.17)\end{array}$ & $\begin{array}{l}0.00 \\
(0.54)\end{array}$ & $\begin{array}{l}0.00 \\
(0.47)\end{array}$ \\
\hline CARRY & & & & $\begin{array}{l}0.01^{* * *} \\
(4.31)\end{array}$ & & & & & $\begin{array}{l}-0.02^{* * *} \\
(-3.60)\end{array}$ & \\
\hline Global Tail & & & & & $\begin{array}{l}-0.04 * * * \\
(-4.73)\end{array}$ & & & & & $\begin{array}{l}-0.03^{* * *} \\
(-3.85)\end{array}$ \\
\hline GRS & 4.27 & 1.01 & 4.66 & 1.05 & 4.01 & 2.31 & 1.15 & 2.03 & 2.80 & 1.58 \\
\hline p-value (\%) & 0.04 & 41.80 & 0.02 & 39.47 & 0.07 & 3.40 & 33.52 & 6.20 & 1.16 & 15.15 \\
\hline RMSE (\%) & 0.28 & 0.20 & 0.31 & 0.07 & 0.16 & 0.27 & 0.12 & 0.27 & 0.18 & 0.04 \\
\hline$R^{2}(\%)$ & 8.52 & 50.16 & -12.90 & 94.60 & 67.30 & -38.17 & 73.16 & -39.70 & 40.34 & 96.77 \\
\hline
\end{tabular}

This table reports the results of the asset pricing tests on the cross-section of currency carry and momentum portfolios. MKT is the return of the S\&P 500 index; DR is the downside risk factor, defined as MKT times an indicator function that takes the value of 1 when MKT $<0$; DOL is the dollar risk factor; CARRY is the high-minus-low currency carry return factor; and the Global Tail factor is the long-short portfolio of the US tail-beta-sorted portfolio returns. We run the Fama-MacBeth regressions and report the estimated risk prices, errors-in-variables corrected t-statistics (in parentheses), root-mean-squared pricing errors (RMSE), and cross-sectional $R^{2}$ 's. We also report the GRS test statistics and p-values on the null hypothesis that the pricing errors are jointly zero. $*, * *$, and ${ }^{* *}$ represent $10 \%, 5 \%$, and $1 \%$ significance levels. The sample period runs from February 1995 to April 2018. 
Table 12: Asset Pricing Tests for Carry and Momentum Portfolios

\begin{tabular}{|c|c|c|c|c|c|}
\hline & CAPM & $\begin{array}{c}\text { DR- } \\
\text { CAPM }\end{array}$ & DOL & FX & $\begin{array}{c}\text { Global } \\
\text { Tail }\end{array}$ \\
\hline MKT & $\begin{array}{l}0.00 \\
(0.62)\end{array}$ & $\begin{array}{l}0.00 \\
(-0.37)\end{array}$ & & & \\
\hline $\mathrm{DR}$ & & $\begin{array}{l}-0.03^{* * *} \\
(-4.01)\end{array}$ & & & \\
\hline DOL & & & $\begin{array}{l}0.00 \\
(0.62)\end{array}$ & $\begin{array}{l}0.00 \\
(0.36)\end{array}$ & $\begin{array}{l}0.00 \\
(0.65)\end{array}$ \\
\hline CARRY & & & & $\begin{array}{l}0.01^{* * *} \\
(3.44)\end{array}$ & \\
\hline Tail & & & & & $\begin{array}{l}-0.03 * * * \\
(-6.02)\end{array}$ \\
\hline GRS & 3.32 & 1.30 & 3.46 & 1.61 & 2.95 \\
\hline p-value (\%) & 0.02 & 22.06 & 0.01 & 8.94 & 0.07 \\
\hline RMSE (\%) & 0.30 & 0.18 & 0.30 & 0.24 & 0.13 \\
\hline$R^{2}(\%)$ & -27.60 & 50.36 & -27.62 & 18.38 & 74.69 \\
\hline
\end{tabular}

This table reports the results of the asset pricing tests on the joint cross-section of currency carry and momentum portfolios, and on the joint cross-section of currency carry and momentum portfolios. MKT is the return of the S\&P 500 index, DR is the downside risk factor, which is defined as MKT times an indicator function that takes the value of 1 when $\mathrm{MKT}<0$; DOL is the dollar risk factor; CARRY is the high-minus-low currency carry trade factor; and the Global Tail factor is the long-short portfolio of the US tail-beta-sorted portfolio returns. We run the Fama-MacBeth regressions and report the estimated risk prices, errors-in-variables corrected t-statistics (in parentheses), root mean squared pricing errors (RMSE), and cross-sectional $R^{2}$ 's. We also report the GRS test statistics and p-values on the null hypothesis that the pricing errors are jointly zero. *, **, and ${ }^{* * *}$ represent $10 \%$, 5\%, and 1\% significance levels. The sample period runs from February 1995 to April 2018. 
Table 13: Asset Pricing Tests for Carry and Momentum Portfolios with Control Factors

\begin{tabular}{llllll}
\hline Panel A: Correlations & \multicolumn{5}{l}{} \\
\hline & CARRY & $\Delta$ FXvol & $\Delta$ GRIX & $\begin{array}{l}\text { Dollar } \\
\text { Carry }\end{array}$ & $\begin{array}{c}\text { Global } \\
\text { Dol }\end{array}$ \\
\hline Global Tail (All countries) & -0.16 & -0.05 & -0.04 & -0.35 & -0.16 \\
Global Tail (DM) & -0.09 & -0.02 & -0.24 & -0.41 & -0.08 \\
\hline & & & & & \\
Panel B: All Countries & & & & & \\
\hline DOL & -0.001 & -0.001 & 0.000 & 0.001 & -0.001 \\
& $(-0.49)$ & $(-0.81)$ & $(0.08)$ & $(0.39)$ & $(-0.46)$ \\
Global Tail & $-0.019^{* * *}$ & $-0.019^{* * *}$ & $-0.029^{* * *}$ & $-0.030^{* * *}$ & $-0.023^{* * *}$ \\
& $(-4.77)$ & $(-4.61)$ & $(-5.49)$ & $(-5.61)$ & $(-5.74)$ \\
Control & $0.006^{* * *}$ & -0.052 & -0.124 & 0.003 & $-0.008^{* * *}$ \\
& $(3.39)$ & $(-1.44)$ & $(-0.93)$ & $(0.76)$ & $(-2.79)$ \\
GRS & 1.34 & 3.10 & 2.54 & 2.74 & 3.33 \\
p-value (\%) & 19.58 & 0.04 & 0.40 & 0.16 & 0.02 \\
RMSE (\%) & 0.06 & 0.08 & 0.12 & 0.13 & 0.07 \\
$R^{2}(\%)$ & 93.20 & 90.58 & 84.37 & 74.75 & 91.52 \\
\hline
\end{tabular}

This table reports the results for the asset pricing tests on the cross-section of currency carry and momentum portfolios after including other control factors in addition to the global US tail factor (Global Tail). The control factors include the carry trade risk factor (CARRY) in Lustig et al. (2011); the change in foreign exchange volatility ( $\Delta \mathrm{FXvol})$ in Menkhoff et al. (2012a); the index of global ex-ante tail risk concerns ( $\Delta$ GRIX) in Gao et al. (2018); the dollar carry in Lustig et al. (2014); and the global Dollar in Verdelhan (2018). We obtain the GRIX data from the website of Zhaogang Song: https://sites.google.com/ a/cornell.edu/zgs/. The Global Dollar factor data is obtained from the website of Adrien Verdelhan. Panel A reports the correlation coefficients between the global tail factor and the control factors for the sample with all currencies and for that with the currencies from developed markets. We run the Fama-MacBeth regression and report the estimated risk prices, errors-in-variables corrected t-statistics (in parentheses), root-mean-squared pricing errors (RMSE), and cross-sectional $R^{2}$ 's in Panel B. We also report the GRS test statistics and p-values on the null hypothesis that the pricing errors are jointly zero. ${ }^{*},{ }^{* *}$, and ${ }^{* * *}$ represent $10 \%, 5 \%$, and 1\% significance levels. The sample period runs from February 1995 to April 2018, except for $\Delta$ GRIX, when the sample runs from January 1996 to June 2012. 